\title{
OPINIONES Y EXPERIENCIAS EN EL DESEMPEÑO DE LA DIRECCIÓN ESCOLAR DE LAS MUJERES DIRECTORAS EN ANDALUCÍA
}

\section{[Andalusian women principals' opinions and experiences about their school management performance]}

por

$\underline{\text { Article record }}$

About authors

HTML format
Ficha del artículo

$\underline{\text { Sobre los autores }}$

Formato HTML

\begin{abstract}
This paper aims to identify the opinions and experiences in school management held by women principals in Andalusian early and elementary public schools. Using the survey method, data were collected through a questionnaire from a sample of 206 principals selected through a several-stages procedure. Results show that most women principals were middle-aged, have an extensive professional experience and have no children or other people under their care. They occupied the headship due to altruistic and personal reasons, and they considered the lack of support from Educational Administration as the main problem they have to cope. Also, they conceived their work as a team effort with a facilitator function.
\end{abstract}

\section{Keywords}

School management perfomance; educational leadership; women principals; survey; leadership profile.

\section{Erir}

Resumen
Este trabajo persigue identificar las opiniones y experien-
cias ante la dirección escolar de las directoras de centros
públicos de Educación Infantil y Primaria en Andalucía.
Se realizó un estudio tipo encuesta con una muestra de
206 directoras seleccionada mediante un muestreo polie-
tápico, utilizando el cuestionario para la recogida de in-
formación. Los resultados muestran que las directoras tie-
nen mediana edad, una dilatada experiencia profesional y,
en su mayoría, están relativamente libres de cargas fami-
liares. Accedieron al cargo por razones altruistas y perso-
nales, y señalan la falta de apoyo de la Administración
como su principal problema. Conciben su función como
una labor de equipo eminentemente facilitadora.

\section{Descriptores}

Desempeño de la dirección escolar; liderazgo educativo; mujeres directoras; estudio tipo encuesta; perfil de liderasgo.

\section{EL ACCESO DE LAS MUJERES A LA DIRECCIÓN DEL CENTRO ESCOLAR}

En general, la enseñanza es una profesión con gran presencia de mujeres. Sin embargo, la presencia femenina y masculina es muy desigual según los diferentes niveles, mate- rias o áreas profesionales y, también según los puestos de responsabilidad. En el trabajo de Muñoz-Repiso (2003), se pone de manifiesto que en el contexto europeo, mientras que alrededor del $75 \%$ del profesorado en enseñanza primaria son mujeres (llegando al 95\% en el caso de infantil), tan sólo un 50\% de ellas desempeña puestos de dirección. En 
nuestro país las cifras son similares: según el estudio de Grañeras (2003), mientras que casi el $63 \%$ del profesorado de infantil y primaria son mujeres, sólo un 42,21\% de las docentes ejercen como directoras. En la C.A. Andaluza, durante el curso 2003/04, en primaria e infantil había un 65,6\% de profesoras y sólo un 33,6\% de ellas ejercían la dirección escolar. En cursos anteriores (2000/01), estas cifras era aún más desiguales: un $29,13 \%$ de directoras frente $70,78 \%$ varones directores.

A ello hay que añadir que no sólo es más frecuente encontrar hombres en las tareas de dirección, sino que también nos los encontramos con más frecuencia en los centros más grandes y con mayor número de alumnado y profesorado. Como sugiere el estudio de Díez Gutiérrez (2004), el tamaño de los centros parece estar en relación con la imagen social de poder que se tiene de ellos, con la dificultad o envergadura de la tarea a desempeñar y con el nivel de lucha y competencia por el acceso y el ejercicio del poder en los mismos. Por tanto, la superioridad femenina en cuanto a número no está equiparada en las organizaciones educativas con su presencia en los puestos de responsabilidad y de poder (Bardisa, 1995).

Y, sin embargo, el acceso de la mujer a puestos de dirección es una de las condiciones esenciales de la práctica de la igualdad en el seno de las organizaciones. No podemos hablar de igualdad plena si no existe una participación en igualdad en la toma de decisiones, bien sea política, social o educativa. Por ello, el acceso de las mujeres a los puestos de dirección de cualquier organización resulta fundamental.

En este sentido, desde la década de los ochenta es apreciable el incremento de la atención por cuestiones como las experiencias de las mujeres en la gestión, o las barreras existentes en su desempeño y el potencial para transformar las propias prácticas de gestión. La incorporación de la perspectiva de género en el análisis organizativo y, en concreto, en la comprensión de procesos como la gestión y el liderazgo, supone una oportunidad para profundizar en la constitución de las relaciones sociales y de poder consustanciales a la realidad organizativa.

En la mayoría de los casos, las teorías de la gestión se han basado en observaciones de gestores masculinos y, en consecuencia, los esquemas para definir y poner en práctica un liderazgo eficaz han excluido los atributos propios de la feminidad (Coronel, Moreno, Padilla, 2002). Por esta razón, es necesario que la investigación comience a explorar la experiencia femenina en la dirección de organizaciones en general, $y$, en particular, en las organizaciones educativas. ¿Qué motivos las impulsan a acceder a los cargos de dirección?, ¿cuáles fueron los problemas y dificultades que sufrieron para llegar a ellos y para ejercerlos?, ¿es diferente la forma de liderazgo que ejercen las mujeres?, ¿cuáles son los rasgos que la caracterizan? ¿y las consecuencias para la organización?...

\section{LIDERAZGO Y EXPERIENCIAS DE LAS MUJERES EN LOS PUESTOS DE RESPONSABILIDAD DE LOS CENTROS EDUCATIVOS}

El liderazgo de una organización implica una capacidad de influencia que es adquirida sobre y desde bases informales (López y Sánchez, 1997). Así, mientras que el poder de naturaleza formal es un poder legítimo, de cumplimiento de normas establecidas por la organización pertinente, el liderazgo es de carácter informal, establecido según las características personales del sujeto, así como de su experiencia en otros ámbitos, de sus conocimientos, destrezas de comunicación, etc. El poder de naturaleza informal surge a través de relaciones espontáneas entre los miembros de la organización.

Como se ha sugerido anteriormente, el concepto de liderazgo se ha nutrido de la investigación basada en la experiencia de 
gestores masculinos. Ello, unido al influjo del enfoque positivista, ha llevado a un modelo de liderazgo burocrático y de gestión, que lo entiende como autoridad de oficio y dependiente de una variedad de estrategias dispuestas para el logro de metas, como función de una posición en la organización. La razón para ejercerlo no es el cambio social, sino el desarrollo de habilidades eficaces de gestión para el éxito de ciertas metas organizativas (Coronel, Moreno y Padilla, 2002).

Sin embargo, otros acercamientos posteriores más actuales al trabajo de gestión y ejercicio de liderazgo se esfuerzan por minimizar el carácter técnico acudiendo a dimensiones más simbólicas y sociales, siendo el componente de interacción una pieza clave (Coronel, 1996 y 2005; Grace, 1995; Rost, 1994). Así entendido, el liderazgo exige la concurrencia de elementos como la influencia, el cambio intencionado y los propósitos comunes, y se diferencia decisivamente de la gestión. De este modo, el cambio en las escuelas viene a ser efecto del ejercicio de un liderazgo compartido que se proyecta sobre todos los aspectos presentes en la vida escolar (Batanaz, 2005). En el escenario educativo interactúan múltiples líderes que se solapan y complementan; no es simplemente una función de lo que sabe y hace el director o directora o cualquier otro/a líder individual.

Como plantea Coronel (2005), la conveniencia de ver el liderazgo menos como un estilo de conducta o técnica de gestión y más como expresión cultural de la organización, nos lleva a atender a su carácter social y cultural, y otorga al concepto una dimensionalidad mayor en el conjunto de la actividad organizativa, por cuanto que atiende a la totalidad de los procesos organizativos, afectando más que a las acciones de los individuos al sistema en que estas ocurren.

La función del liderazgo en la escuela es movilizar a las personas comprometidas con ella para hacer que el modo como actúan colectivamente se oriente a satisfacer las necesidades del alumnado y las demandas de la sociedad (Donaldson, 2000). Por ello, el liderazgo encierra un componente ético que debe asentarse bajo tres dimensiones (Starrat, 1991): la crítica, la justicia y el cuidado. Por sí mismas, estas dimensiones no ofrecen un marco adecuado para realizar juicios éticos; sin embargo, juntas se complementan en el contexto de la práctica, en el desarrollo de la comunidad.

El liderazgo educativo está mediatizado por el contexto organizativo en el que se desarrolla y favorece que las escuelas pasen de ser organizaciones a ser comunidades democráticas de aprendizaje (Coronel, 2003 y 2005); una comunidad democrática se centra en la igualdad y la justicia y se implica en todos los niveles de la vida social e institucional. Esto sugiere que el liderazgo reside en la comunidad, adquiere un carácter colectivo y se enfoca al cambio.

Lorenzo (1997) plantea que el liderazgo se conceptualiza como una función, una cualidad y una propiedad que reside en el grupo y que dinamiza la organización. Al ser una función, se habla más de liderazgo que de líder; es estratégica para toda la organización, condiciona ritmos de trabajo, crea impulsos, orienta las energías colectivas hacia metas determinadas, construye una visión de la organización. Es compartida, en el sentido de que se distribuye y se derrama por todas las unidades organizativas. Se ejerce colegiada y colaborativamente. Se inserta en la cultura, siendo uno más de los valores que constituyen la cultura de esa organización. $\mathrm{Y}$, por último, reside en el grupo, pero en su ejercicio influyen factores y cualidades personales como la exactitud en la percepción de papeles y situaciones, la formación, las expectativas, los valores, etc.

Los problemas y retos escolares son responsabilidad de toda la comunidad, lo que implica la necesidad de crear los espacios y tiempos necesarios para que las personas que la forman compartan y contribuyan a lo que 
ocurre en la organización: implica una responsabilidad compartida a la hora de identificar problemas, explorar soluciones, construir una visión compartida y emprender acciones de mejora trabajando conjuntamente (Doyle y Smith, 2001; Morrison, 2002).

Como sugiere González (2003), el equipo directivo ha de convertirse en "arquitectos del liderazgo", dedicando su atención a la construcción de equipos, al desarrollo de una toma de decisiones compartida y de la colegialidad, descubriendo, posibilitando y potenciando las habilidades y conocimientos de las personas de la organización, manteniendo unidas las distintas piezas de la organización y apoyando el que las personas de las mismas se sientan responsables de su contribución al resultado colectivo (Elmore, 2000; Gago, 2003).

En este sentido, cuando la dirección se caracteriza por un auténtico liderazgo pedagógico o educativo, es más fácil que todo el equipo directivo llegue a constituir un grupo homogéneo orientado hacia este tipo de liderazgo y que incluso ello se extienda al resto del profesorado. Así, el liderazgo ejercido por la dirección debe ser eminentemente pedagógico (Gento y Ruíz, 1996), lo que implica que su preocupación fundamental ha de ser la promoción de la potencialidad de los miembros del centro orientada a lograr una educación de calidad.

En este contexto, se ha sugerido que, pese a su escasa presencia en los puestos de responsabilidad en las instituciones escolares, es posible que las mujeres cuenten con habilidades comunicativas y sociales adecuadas para las exigencias de unas organizaciones democráticas y participativas (Asplund, 1998). Lo que nos lleva a considerar la necesidad de estudiar a las mujeres en los procesos de gestión y liderazgo. Desde las investigaciones con perspectivas de género se ha profundizado en torno a cuatro temas básicos (Reynolds, 1995): la ausencia de mujeres en la administración y el liderazgo, las expe- riencias de las mujeres líderes, las barreras y estrategias para las mujeres (discriminación de las estructuras, minimización/exageraciones de las diferencias, etc.), y la reconstrucción del discurso del liderazgo en las organizaciones desde el punto de vista político.

Si bien son pocos, existen trabajos -sobre todo provenientes del contexto anglosajónque han indagado en las características del estilo de liderazgo y gestión femenino (e.g., Capper, 1995; Fennell, 1997; Goldring y Chen, 1992; Hall y Southworth, 1997; Hurty, 1995; Lips, 1991; Mertz, 1995). Entre las aportaciones de estos estudios, debemos destacar aspectos como los siguientes:

- El énfasis en las personas y en los procesos.

- La concepción del liderazgo como responsabilidad de todos/as.

- La constitución de estructuras menos burocratizadas, priorizando las relaciones sociales.

- La capacidad para activar conexiones con las personas y el "aprender con los demás".

- Una tendencia a "dejar hacer”, potenciando profesionalmente el trabajo y las ideas de los grupos.

- La participación y el diálogo como procesos educativos.

- Una clara preferencia por un enfoque de tipo cooperativo y consultivo.

- Un estilo colaborativo, compartido y no competitivo.

- El énfasis en los procesos democráticos.

- El desarrollo de políticas de cuidado y apoyo mutuo.

Basándose en estos y otros trabajos, autoras y autores como Bardisa (1995), Barquín y Melero (1994) y Sarrió, Ramos y Candela (2004) concluyen que en muchos de los casos en que las mujeres acceden a los puestos de responsabilidad en los centros educativos o en la inspección, utilizan estilos de ejercer la responsabilidad y el poder que se deriva de esos cargos de forma muy diferente a los 
de los hombres. En general, se refiere cierto rechazo por parte de las mujeres de una dirección sustentada en características como la fuerza, la imposición y el dominio, frente a un tipo de atención al otro basado en la mediación, la colaboración y la empatía.

Parece, por tanto, que las mujeres líderes desarrollan un estilo de liderazgo que concede más importancia a la colaboración y a la pedagogía, orientado hacia las personas, las necesidades individuales y los procesos, más creativo, comunicativo y abierto, y que promueve la potenciación profesional y el compromiso colectivo de los miembros de la organización y conlleva una mejora de las escuelas.

En general, estas investigaciones representan una alternativa, un enfoque diferente en la investigación sobre la gestión y el liderazgo en las organizaciones educativas, pero es evidente que necesitamos más estudios en nuestro país que documenten las experiencias de las mujeres que gestionan y lideran nuestros centros educativos.

\section{MÉTODO}

Se ha utilizado el método de encuesta cuyas características son la formulación de preguntas y la pretensión de generalizar los resultados a la población, rasgos que justifican precisamente su elección en nuestro estudio.

\section{Objetivo}

El objetivo principal de este trabajo es identificar las opiniones y experiencias que las directoras de centros escolares públicos de Educación Infantil y Primaria en Andalucía tienen ante la dirección escolar. Esto implica explorar aspectos como las razones por las que accedieron al cargo, los problemas o situaciones que afrontan, la forma en que entienden la práctica de la dirección escolar y la valoración que hacen de sus propias cualidades y su desempeño. Se pretende también identificar posibles diferencias de opinión entre las directoras en función de variables demográficas como la provincia, el nivel educativo, el tipo de centro, la experiencia docente, la edad y el tener o no hijos/as a su cargo.

\section{Población y muestra}

La población del estudio estaba compuesta por el total de las directoras (521) de los centros públicos de educación infantil y primaria de Andalucía. Para la selección muestral se siguió un procedimiento polietápico que combinó un muestreo aleatorio estratificado con asignación proporcional, para la selección de las directoras por cada provincia andaluza, con un muestreo aleatorio sistemático, para la elección de las unidades maestrales. El tamaño final de la muestra y su distribución respecto a las provincias andaluzas se recoge en la tabla 1 . Para ese tamaño, y con un nivel de confianza del 95\%, el error muestra asciende al 5\%.

\begin{tabular}{|l|c|c|}
\cline { 2 - 3 } \multicolumn{1}{c|}{} & $\begin{array}{c}\text { Porcentaje de } \\
\text { contribución }\end{array}$ & $\begin{array}{c}\mathbf{N}^{\mathbf{0}} \text { de directoras } \\
\text { incluidas }\end{array}$ \\
\hline Almería & 14.56 & 30 \\
\hline Cádiz & 5.83 & 12 \\
\hline Córdoba & 11.65 & 24 \\
\hline Granada & 15.53 & 32 \\
\hline Huelva & 7.28 & 15 \\
\hline Jaén & 13.11 & 27 \\
\hline Málaga & 14.10 & 29 \\
\hline Sevilla & 17.96 & 37 \\
\hline Total en C.A.Andal. & --- & 206 \\
\hline
\end{tabular}

Tabla 1. Composición de la muestra por provincias 


\section{Técnica de recogida de datos}

Se diseñó un cuestionario ad-hoc para recoger la información relativa a los distintos objetivos del estudio teniendo como referencia el instrumento usado en un estudio similar (Díez Gutiérrez, 2004). El instrumento contiene tres bloques de preguntas, de los que aquí hacemos referencia a dos de ellos:

- En el primer bloque (21 preguntas), denominado Información de carácter profesional y vital, se recaba información referida a: datos sobre el centro en el que trabajan las encuestadas (número de unidades, localización, etc.), datos profesionales (nivel educativo que imparten, antigüedad, experiencia docente, etc.), y datos personales y familiares (edad, hijos/as a su cargo, etc.).

- En el segundo bloque (Opiniones y experiencias ante la dirección escolar), se incluyen un total de 13 preguntas que persiguen identificar las opiniones de las directoras encuestadas ante la dirección escolar, así como describir algunas de las características más relevantes de su experiencia ante el cargo. Las cuestiones indagan sobre temas como: los aspectos que se ven más y menos afectados por el tiempo que requiere la dirección, el grado en las actividades domésticas y familiares condiciona el rendimiento profesional, la importancia relativa de distintos incentivos para el acceso al cargo, las competencias y cualidades que requiere la dirección y las competencias y cualidades que creen poseer, los aspectos en los que perciben un cambio en sus colegas desde que ocupa el cargo, los principales problemas que ha encontrado a la hora de desempeñarlo, la valoración y reconocimiento de su trabajo por parte de distintas instancias (colegas, Administración, alumnado, familias, etc.), la importancia relativa de distintas tareas propias de la dirección, estilo de resolución de problemas de disciplina, forma en que entiende la dirección, número de horas que invierte en diferentes tareas propias del cargo y, finalmente, se le pide una auto-valoración global de su actuación.

A ellos se une una escala (compuesta por 7 dimensiones y 36 ítems) sobre las barreras que las docentes pueden experimentar a la hora de optar por el desempeño de un cargo directivo, que responde a otros fines de la investigación.

\section{Procedimientos utilizados en el análisis de datos}

Para el análisis de la información se han estimado los porcentajes de respuesta así como los estadísticos descriptivos de tendencia central (concretamente, la media, la mediana y la moda) y de dispersión (desviación típica) para los diferentes ítems y preguntas.

Para identificar las diferencias de opinión entre las directoras se han utilizado diferentes estadísticos de contraste: chi-cuadrado para las variables nominales y, en el resto, la prueba t de contraste de medias y el ANOVA (en función del número de grupos a comparar). En todos los casos se ha trabajado con un nivel de confianza del 95\%.

\section{RESULTADOS}

\section{Información profesional y vital}

En la Ilustración 1 se puede apreciar la procedencia de las directoras según las diferentes provincias de la C.A. Andaluza. Así, las provincias con mayor representación de directoras en nuestra muestra son, por este orden, Sevilla (que aporta un $18 \%$ de directoras), Granada (15,5\%), Almería $(14,6 \%)$ y Málaga (14,1\%), que se corresponden, en su mayor parte, con las provincias con más centros educativos. Por su parte, las provincias que aportan menos directoras al estudio son Cádiz (6\%) y Huelva (7,5\%). 


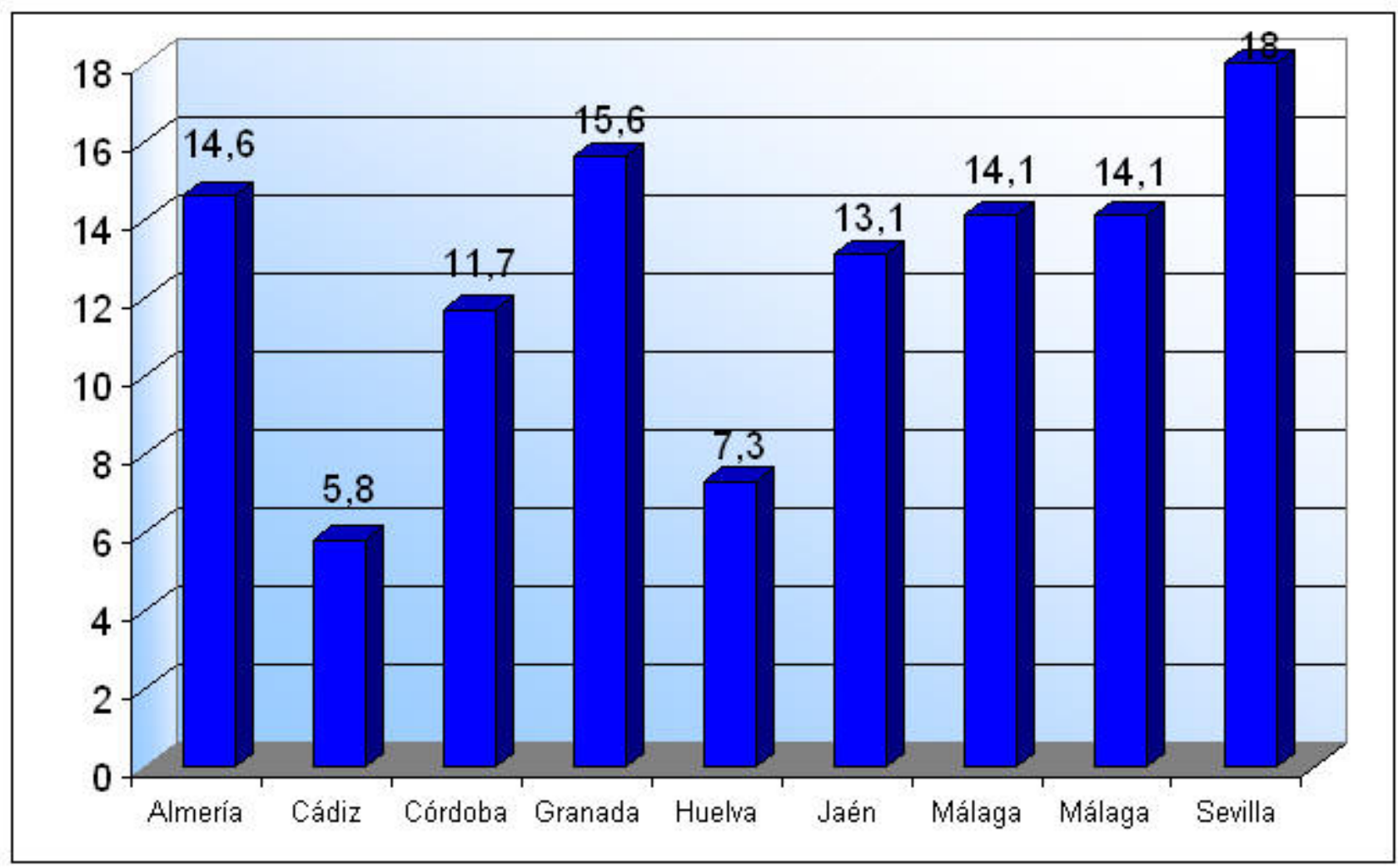

Ilustración 1 Porcentaje de directoras por provincia

En la tabla 2 hemos sintetizado la información más relevante sobre los centros en los que trabajan las directoras encuestadas. Según podemos apreciar, en su mayoría, estas docentes dirigen centros urbanos (un 44,3\%), un $19,9 \%$ urbanos-periféricos y un 35,8\% lo hacen en centros rurales. Además, el promedio de unidades de las que se componen sus centros es cercano al valor 14 (con una desviación de 6,7), siendo el valor más frecuente 9; es decir, predominan los centros de 9 uni- dades entre los que lideran las directoras de la muestra.

Es interesante destacar, por otro lado, que en esos centros predomina el profesorado femenino (media $=14,38$ ) frente al masculino (media cercana a 5), situación que suele ser bastante habitual en los centros de enseñanza, en general, pero especialmente en los que imparten Educación Infantil y Primaria. De acuerdo con los promedios señalados, puede decirse que en estos centros existen casi 3 profesoras por cada docente varón.

\begin{tabular}{|c|c|c|}
\hline \multicolumn{3}{|c|}{ CARACTERÍSTICAS DE LOS CENTROS LIDERADOSPOR LAS DIRECTORAS } \\
\hline \multirow{3}{*}{ TIPO DE CENTRO: } & Urbano & $44,3 \%$ \\
\hline & Rural & $35,8 \%$ \\
\hline & Urbano-periférico & $19,9 \%$ \\
\hline \multirow{3}{*}{$\mathrm{N}^{\circ}$ DE UNIDADES: } & Media & 13,69 \\
\hline & Moda & 9,00 \\
\hline & Desviación Típica & 6,71 \\
\hline \multirow[b]{2}{*}{ SEXO DEL PROFESORADO: } & Promedio de profesoras & $14,38\left(\mathrm{D} . \mathrm{T}^{[1]} \cdot\right.$ profesoras 6,5$)$ \\
\hline & Promedio de profesores & 4,80 (D.T. profesores 3,0) \\
\hline
\end{tabular}

Tabla 2. Características generales de los centros que dirigen las directoras 
En la tabla 3 se presenta una síntesis de la información de tipo profesional que hemos considerado relevante para nuestro estudio. Como se puede apreciar, las directoras encuestadas imparten más frecuentemente el $3^{\circ}$ ciclo de primaria (40,3\%). Es decir, trabajan con niños y niñas más mayores y, por tanto, más autónomos/as, teniendo de esta forma su trabajo una menor connotación maternal, de cuidado y atención a las criaturas.

\begin{tabular}{|l|l|l|}
\hline \multicolumn{2}{|c|}{ INFORMACIÓN PROFESIONAL GENERAL } \\
\hline \multirow{2}{*}{ NIVEL EDUCATIVO } & Infantil & $25,00 \%$ \\
QUE IMPARTE: & $1^{\circ}$ ciclo Primaria & $11,10 \%$ \\
& $2^{\circ}$ ciclo Primaria & $23,60 \%$ \\
& $3^{\circ}$ ciclo Primaria & $40,30 \%$ \\
\hline AÑOS DE EXPERIENCIA & Media & 23,99 \\
DOCENTE: & Moda & 19,00 \\
\hline AÑOS DE ANTIGÜE- & Desviación Típica & 7,66 \\
DAD EN EL CENTRO: & Modas & 14,25 \\
& Desviación Típica & 5,00 y 6,00 \\
\hline & Jefatura de Estudio & 7,67 \\
\hline DOS ANTERIORMENTE & Secretaría & $54,7 \%$ (Media 4,1 años; D.T.: 4,3) \\
& Otros cargos & $42,8 \%$ (Media 3,1 años; D.T.: 3,9) \\
\hline AÑOS DE EXPERIENCIA & Media & $73,3 \%$ (Media 4,2 años; D.T.: 4,4 ) \\
COMO DIRECTORA: & Moda & 7,43 \\
& Desviación Típica & 3,00 \\
\hline AÑOS EN EL ACTUAL & Media & 5,58 \\
\hline CARGO DE DIRECTORA & Moda & 6,32 \\
& Desviación Típica & 3,00 \\
\hline & Propuesta por la Admón. & 5,32 \\
\hline CONDICIÓN DE ACCE- & Elegida y propuesta por compañeros/as & $57,40 \%$ \\
SO A LA DIRECCIÓN & Elegida y presentándose por propia iniciativa & $31,70 \%$ \\
& Candidata única & $72,00 \%$ \\
\hline COMPETENCIA EN LA & Concurre con colega varón & $17,40 \%$ \\
ELECCIÓN & Concurre con colega mujer & $10,60 \%$ \\
\hline
\end{tabular}

Tabla 3. Características profesionales generales de las directoras de la muestra

Por otra parte, tanto su experiencia docente como su antigüedad en el centro en el que están actualmente son bastante amplias. Así, como término medio, las directoras tienen casi 24 años de experiencia docente -con una desviación mayor de 7 años-, siendo lo más frecuente que tengan 19 años de experiencia. Por tanto, puede pensarse que los cargos de directoras suelen ser ocupados por docentes con una dilatada trayectoria en el campo educativo. Asimismo, se trata de docentes con una considerable antigüedad en el mismo centro (superior a 14 años como promedio).
Su larga trayectoria docente está también avalada por el desempeño de otros cargos antes de llegar a la dirección. Más de la mitad de las encuestadas - un 54,7\%- han sido Jefas de Estudio antes que directoras (durante un promedio de 4 años aproximadamente) y muchas de ellas -en torno al 43\%- han desempeñado la Secretaría de sus centros durante una media de 3 años. Casi tres cuartas partes han ejercido otros cargos durante un promedio superior a los 4 años. En este sentido, cabe destacar el ejercicio del cargo de Coordinadora de Ciclo, con mayor frecuencia que otros cargos relacionados con la gestión (como, por ejemplo, el de Secretaria 
del Consejo) o el apoyo educativo (Equipo de Orientación Educativa).

La experiencia en el desempeño de la dirección alcanza igualmente un promedio bastante alto, cercano a los siete años y medio, siendo lo más frecuente que las directoras lleven 3 años en el ejercicio de la dirección. Este dato concuerda con la información aportada por la variable "años en el cargo actual de directora”. En ella, el promedio es de 6,32 años (D.T. de 5,32) y la moda (o valor más frecuente) es de 3 años. Puede, por tanto, pensarse que, en su mayor parte, el desempeño actual del cargo coincide con la experiencia en la dirección que tienen las encuestadas.

Con relación al acceso al cargo de directora, podemos añadir alguna información adicional. Así, en la mayoría de los casos (más del 57\%) las docentes fueron propuestas por la Administración para desempeñar el cargo, aunque un $42,6 \%$ fue elegida por votación, bien porque se presentaron a iniciativa de los/as compañeros/as (un 11,7\%), bien por iniciativa propia (casi un 31\%). Sorprende, por tanto, el bajo porcentaje con que las directoras han sido previamente propuestas por sus colegas del centro.

De cualquier forma, en los casos en los que hubo un proceso de elección, la gran mayoría de las directoras encuestadas fueron candidatas únicas. Cuando la elección fue en concurrencia con otra persona, la mayor parte de las veces fue con un colega varón (un $17,40 \%$ frente a un 10,60\%).

La descripción de la muestra de directoras participantes en el estudio requiere también un análisis de algunas variables relacionadas con la esfera personal y familiar (ver tabla 4). Podemos destacar que las directoras encuestadas suelen ser mujeres de cierta edad, estando casi el $90 \%$ de ellas por encima de los 40 años de edad. Esta información, por otra parte, concuerda con la ya expuesta en relación con la trayectoria profesional, según la cual, se trata de mujeres que han pasado muchos años en la enseñanza y en el desempeño de otros cargos antes de acceder a la dirección.

\begin{tabular}{|l|l|l|}
\hline \multicolumn{2}{|c|}{ CARACTERÍSTICAS PERSONALES Y FAMILIARES } \\
\hline & De $20-29$ años & $05,00 \%$ \\
GRUPO DE EDAD & De 30-39 años & $09,90 \%$ \\
& De 40-49 años & $44,10 \%$ \\
& 50 años o más & $45,50 \%$ \\
\hline \multirow{2}{*}{ ESTADO CIVIL: } & Soltera & $12,90 \%$ \\
& En pareja o casada & $77,20 \%$ \\
& Divorciada o separada & $07,90 \%$ \\
& Viuda & $02,00 \%$ \\
\hline HIJOS/AS O FAMILIARES A SU CARGO: & Ninguno & $26,50 \%$ \\
& 1 hijo/a & $23,00 \%$ \\
& 2 hijos/as & $36,70 \%$ \\
& 3 ó más hijos/as & $12,80 \%$ \\
EDAD DEL MÁS PEQUEÑO DE LOS HIJOS: & Otras personas a su cargo & $01,00 \%$ \\
\hline \multirow{2}{*}{ AYUDA DOMÉSTICA: } & Menos de 3 años & $01,40 \%$ \\
& De 3 a 6 años & $12,10 \%$ \\
& De 7 a 12 años & $18,60 \%$ \\
& Más de 12 años & $67,90 \%$ \\
\hline
\end{tabular}

Tabla 4. Información personal y profesional de las directoras de la muestra

En su mayoría, las directoras viven en pareja o están casadas. Tan sólo una cuarta parte de ellas, aproximadamente, presentan otro estado civil (soltería, divor- 
cio/separación o viudedad). Asimismo, las tres cuartas partes de la muestra tienen un/a hijo/a o más, siendo lo más habitual que las directoras tengas 2 hijos/as. Muchas de ellas (un 26,5\%), no obstante, no tienen ningún hijo/a ni ninguna otra persona a su cargo. Esta libertad de cargas familiares (en torno al $50 \%$ de las encuestadas o no tienen hijos/as o tienen sólo uno/a) puede considerarse como una circunstancia favorecedora del desempeño de la dirección. A ello hay que unir el hecho de que las/os hijas/os de estas mujeres son, en general, mayores (la opción "más de 12 años” casi alcanza un porcentaje del $68 \%$ ), y no requieren tanto cuidado como las criaturas más pequeñas (tan sólo un 13\% afirma tener hijos/as por debajo de los 7 años).
En torno al $60 \%$ afirma tener ayuda externa para la realización de las tareas domésticas, mientras que, a nuestro juicio, un alto porcentaje de estas mujeres (más del 40\%) no la tiene.

\section{Opiniones y experiencias ante la direc- ción escolar}

En la tabla 5 se presentan los principales hallazgos encontrados en torno a la dimensión Opiniones y experiencias ante la dirección escolar. En ella se pretende recoger información sobre las creencias y experiencias que estas docentes tienen en relación con la dirección escolar.

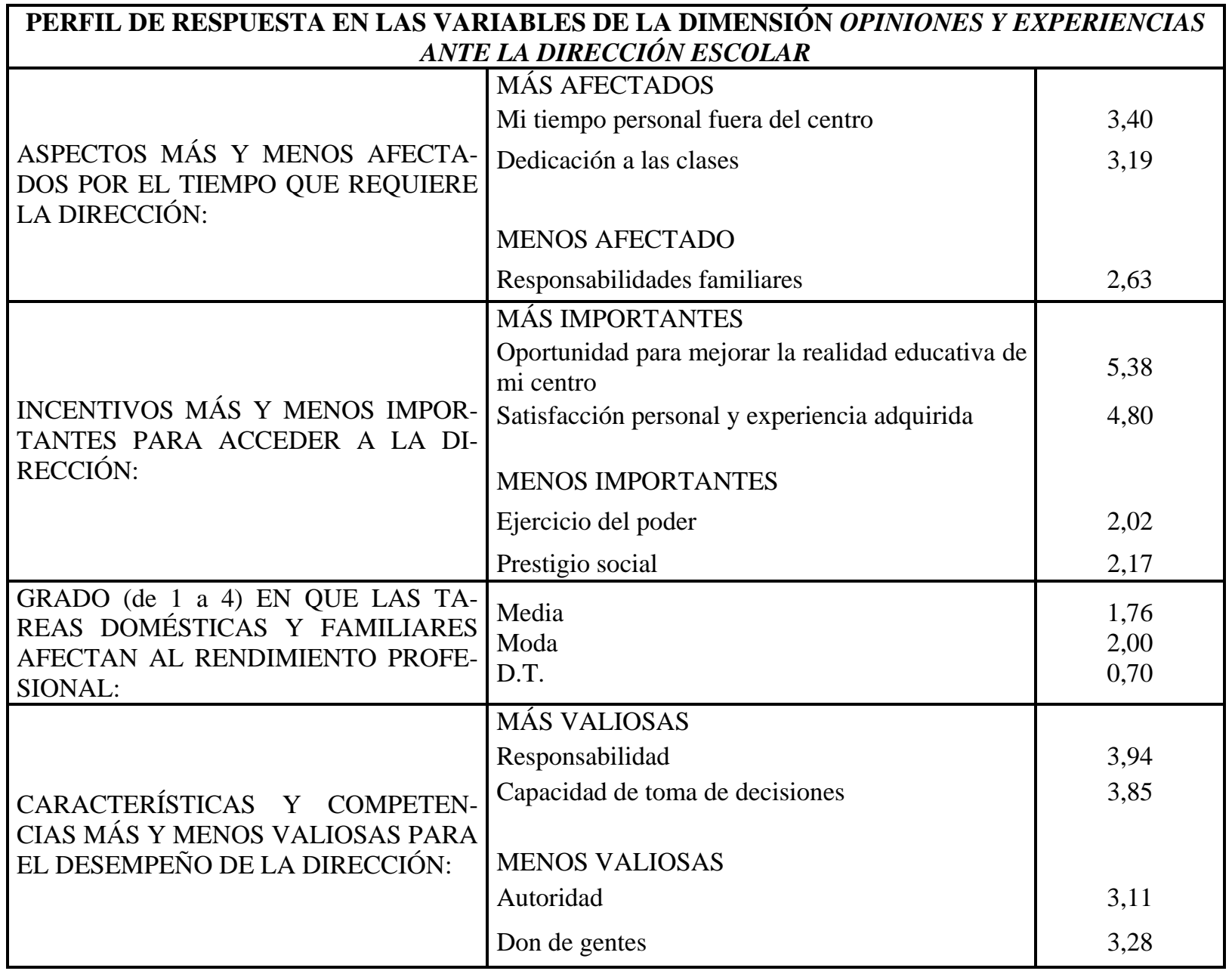

Tabla 5. Opiniones y experiencias ante la dirección escolar 


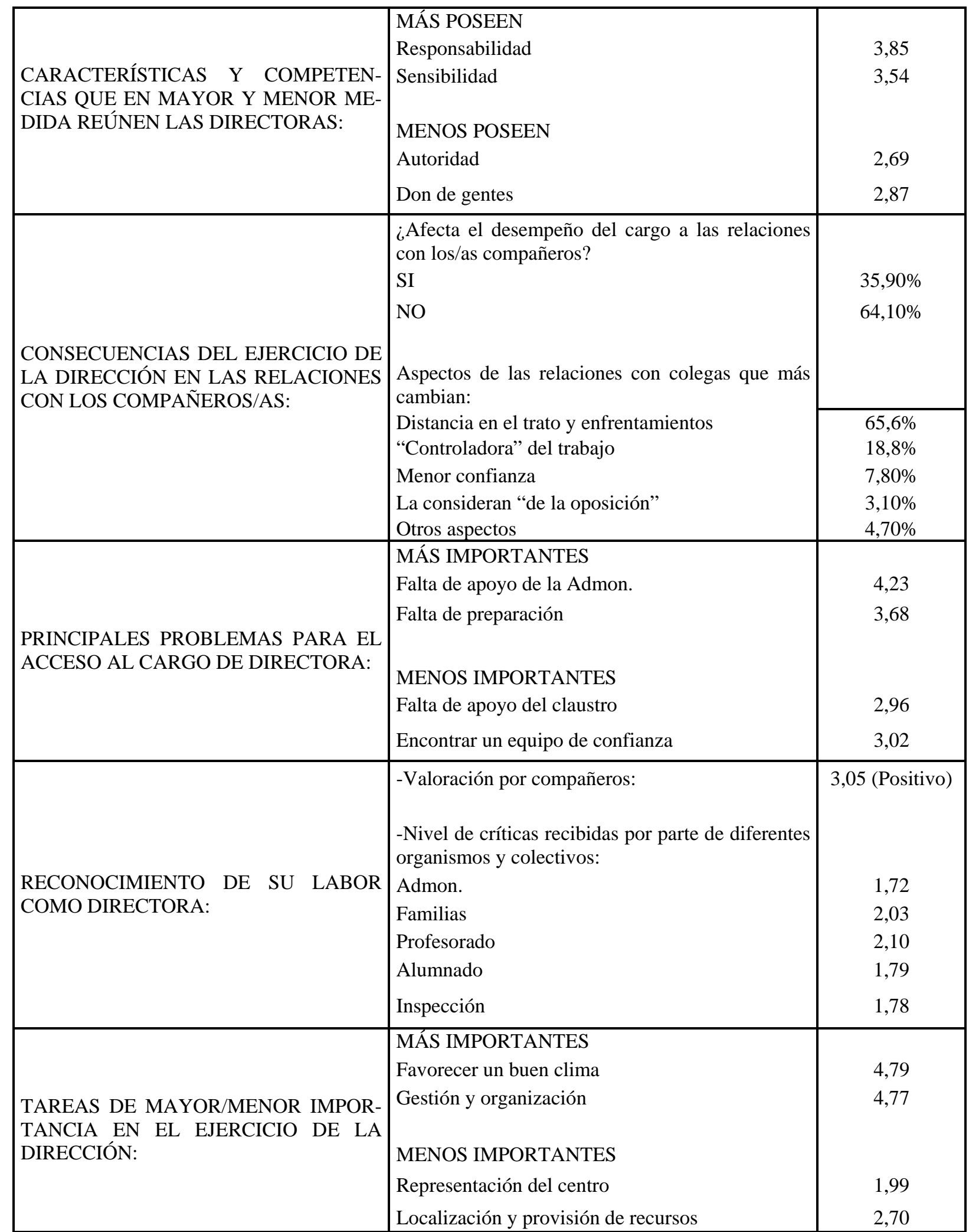

Tabla 5. Opiniones y experiencias ante la dirección escolar (continuación). 


\begin{tabular}{|c|c|c|}
\hline $\begin{array}{l}\text { MECANISMOS PARA LA RESOLU- } \\
\text { CIÓN DE PROBLEMAS DE DISCIPLI- } \\
\text { NA: }\end{array}$ & $\begin{array}{l}\text { Hablar con implicados/as y llegar a acuerdos } \\
\text { Desarrollar programa de mejora de conviv. } \\
\text { Aplicar normativa y R.R.I. } \\
\text { No ha tenido problemas de disciplina } \\
\text { Ser firme y tomar decisiones rápidas }\end{array}$ & $\begin{array}{l}53,2 \% \\
16,8 \% \\
14,2 \% \\
11,1 \% \\
4,70 \%\end{array}$ \\
\hline $\begin{array}{l}\text { FORMA EN QUE ENTIENDE LA DI- } \\
\text { RECCIÓN: }\end{array}$ & $\begin{array}{l}\text { Trabajo en equipo } \\
\text { Gestión } \\
\text { Poder de decisión }\end{array}$ & $\begin{array}{c}85,1 \% \\
13,9 \% \\
1,0 \%\end{array}$ \\
\hline $\begin{array}{l}\text { TAREAS RELACIONADAS CON LA } \\
\text { DIRECCIÓN A LAS QUE SE DEDICAN } \\
\text { MÁS Y MENOS CANTIDAD DE HORAS } \\
\text { SEMANALES: }\end{array}$ & $\begin{array}{l}\text { MÁS } \\
\text { Otras }{ }^{[1]} \\
\text { Administrativas/gestión } \\
\text { MENOS: } \\
\text { Control } \\
\text { Representación } \\
\end{array}$ & $\begin{array}{l}7,87 \\
6,47 \\
1,75 \\
2,07\end{array}$ \\
\hline $\begin{array}{l}\text { AUTO-VALORACIÓN DE LA ACTUA- } \\
\text { CIÓN: }\end{array}$ & $\begin{array}{l}\text { Media } \\
\text { Moda } \\
\text { D.T. }\end{array}$ & $\begin{array}{l}3,19 \\
3,00 \\
0,63\end{array}$ \\
\hline
\end{tabular}

Tabla 5. Opiniones y experiencias ante la dirección escolar (continuación).

La primera variable incluida en esta dimensión hace referencia a los aspectos que se ven más y menos afectados por el tiempo que requiere la dirección del centro (ver también la ilustración 2). Como se aprecia en la tabla 5 y la ilustración $2^{[3]}$, es el tiempo personal fuera del centro el que se ve mayormente más afectado por el ejercicio de la dirección. La docencia es otro aspecto que se ve mermado por las tareas de gestión, tanto en lo que se refiere a la dedicación a las clases, como a la preparación previa de las mismas. Por su parte, entre las tareas que menos dejan notar el tiempo extra dedicado al cargo, se encuentran las responsabilidades familiares y la atención a los problemas del alumnado.

Es evidente que ser directoras, para estas mujeres, no implica en ningún caso, abandonar o dejar de lado su rol como miembro de una familia (madre y/o esposa), ni la dimensión asistencial o de cuidado que acompaña a la labor docente. Por el contrario, es el tiempo personal (para el ocio, la formación, la participación ciudadana,...) el que se ve afectado o reducido en mayor medida, seguido por la dimensión más académica de la enseñanza: la preparación e impartición de clases. 


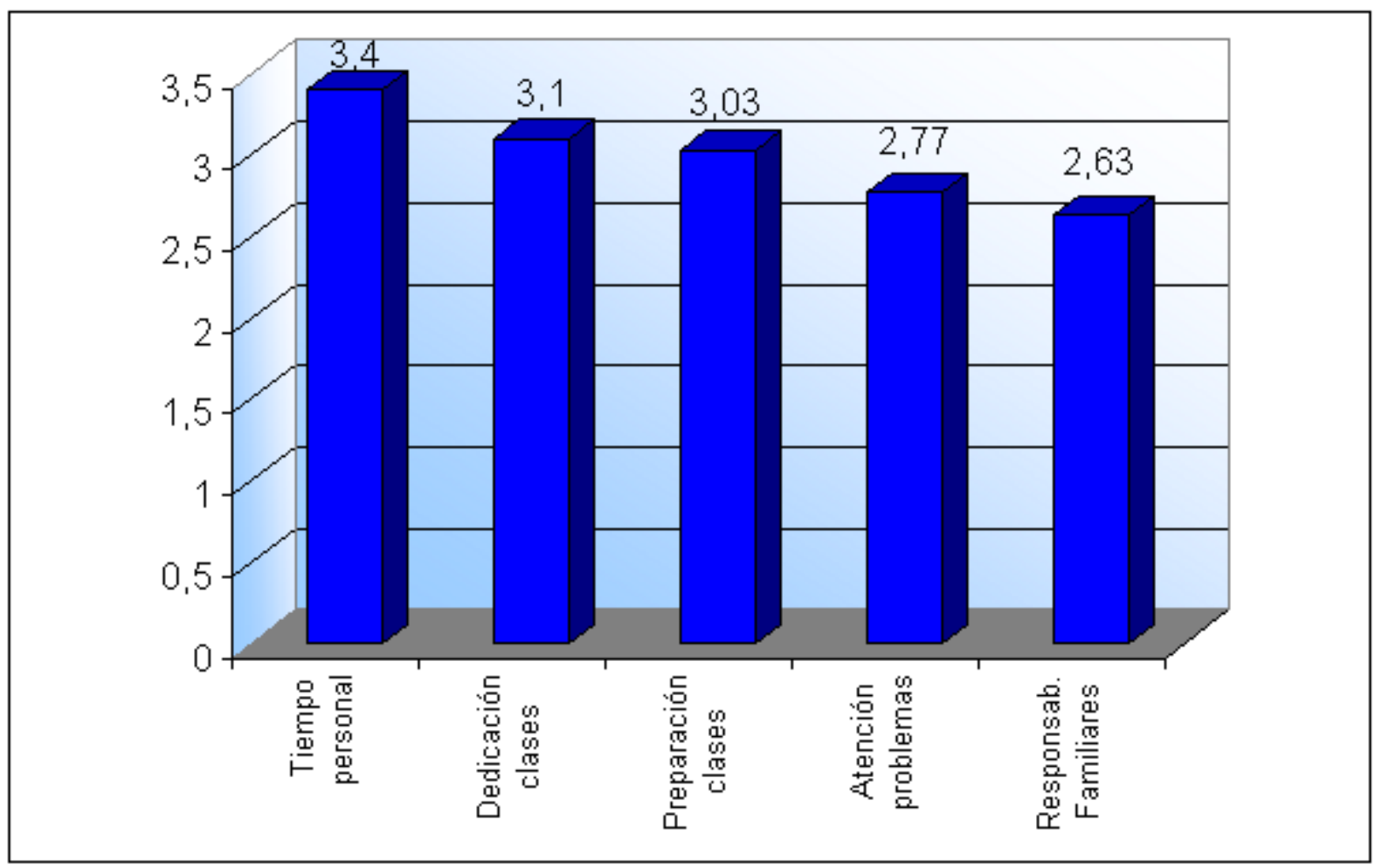

Ilustración 2. Aspectos que se ven más y menos afectados por el ejercicio de la dirección

En este momento, es interesante mostrar la respuesta que las directoras dan ante la pregunta sobre el grado en que las actividades domésticas y familiares condicionan su rendimiento profesional (ver tabla 5). Dicha respuesta se sitúa entre las opciones nada (valor 1) y poco (valor 2), ya que la media obtenida es de 1,76 (con una desviación típica, de 0,70 , lo que indica un cierto grado de acuerdo entre las docentes a la hora de responder). Es decir, según las encuestadas su dedicación a la familia y el hogar tiene escasa incidencia en su rendimiento en el trabajo.

Así pues, en términos generales, la opinión de las directoras sobre las relaciones entre el desempeño del puesto y el cuidado del hogar y la familia parece apuntar a que ninguno de estos dos ámbitos -laboral y familiar-incide negativamente en el otro. Así, desempeñar la dirección no afecta en gran medida a las responsabilidades familiares, ni las responsabi- lidades familiares y domésticas condicionan el rendimiento laboral.

En la dimensión de Opiniones y experiencias ante la dirección, las directoras también indican los principales incentivos que tuvieron para acceder al cargo (ver tabla 5 e ilustración 3). Entre ellos hay que destacar el más importante que fue tener una oportunidad para mejorar la realidad educativa del centro (el promedio de importancia de 1 a 7 obtenido por este indicador es de 5,38), seguido de la satisfacción personal y la experiencia adquirida $(4,8)$ y del compromiso por la igualdad entre los sexos a la hora de asumir responsabilidades (4.08). Los incentivos que, según la muestra, menos le han influido son el ejercicio del poder (2.02) y el prestigio social (2.17). Por su parte, alcanzar una mayor remuneración (2.43) y liberarse parcialmente de la docencia (2.72) obtienen valores intermedios en cuanto a su influencia en la decisión de presentarse a la dirección. 


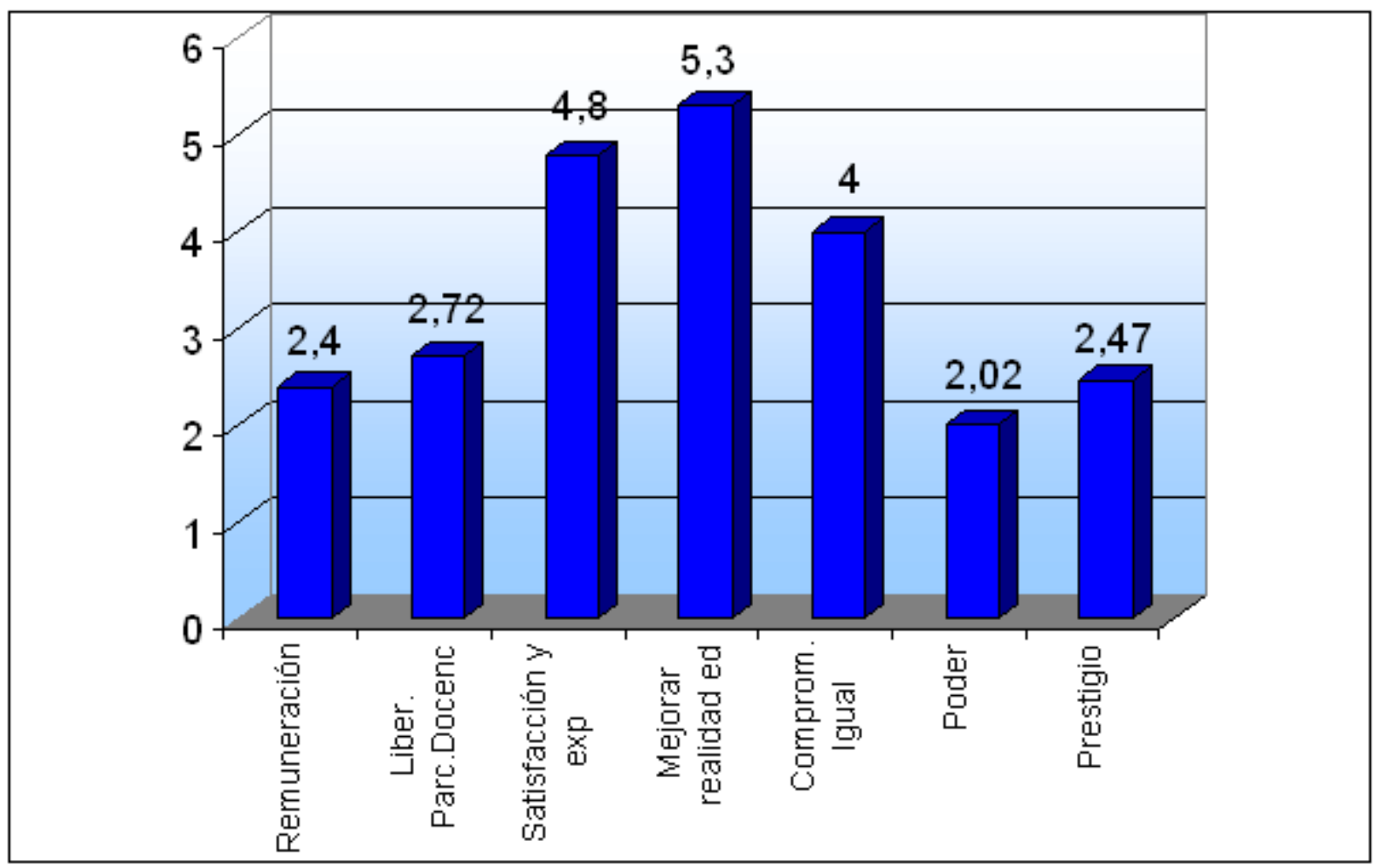

Ilustración 3. Importancia de diferentes incentivos para acceder a la dirección

Pasamos con esto a la pregunta 4 del cuestionario que es una de las más amplias en cuanto al número de variables que engloba; un total de 30 variables que aluden a características y competencias que son valiosas para la dirección (quince primeras) y que poseen las directoras (quince siguientes). Las características y competencias son las mismas para ambas perspectivas, es decir, para juzgar tanto si son valiosas para la dirección como si las directoras las poseen o no. En la tabla 5 se resumen los principales resultados encontrados en esta pregunta, aunque en la tabla 6 se desglosan más específicamente los valores obtenidos en cada una de las variables que engloba.
Podemos destacar, de forma general, que todas las características han sido puntuadas por las directoras como bastante o muy valiosas para el desempeño de la dirección. Según se puede apreciar en la tabla 6, los promedios superan siempre el valor de 3.10 en la columna de la izquierda. Así, las características mejor valoradas son, por este orden, la responsabilidad, la capacidad de toma de decisiones, la habilidad para conjugar situaciones a veces difíciles y conflictivas, la habilidad de mediación en los conflictos y saber planificar y organizar. Se valora, por tanto, la capacidad de gestión, concretada en la toma de decisiones, la organización y la planificación, junto con las habilidades de mediación y resolución de conflictos. 


\begin{tabular}{|l|c|c|c|}
\hline \multicolumn{1}{|c|}{ CARACTERÍSTICAS } & $\begin{array}{c}\text { VALOR PARA LA } \\
\text { DIRECCIÓN }\end{array}$ & POSESIÓN & DIFERENCIA \\
\hline Responsabilidad & 3.94 & 3.85 & .09 \\
\hline Don de gentes & 3.28 & 2.87 & .41 \\
\hline Diplomacia & 3.66 & 3.00 & .66 \\
\hline Autoridad & 3.11 & 2.69 & .42 \\
\hline Sensibilidad & 3.47 & 3.54 & -.07 \\
\hline Inteligencia & 3.37 & 2.99 & .38 \\
\hline Habilidades de liderazgo & 3.47 & 2.74 & .73 \\
\hline Capac. dinamizar grupos & 3.67 & 2.97 & .70 \\
\hline Capac. toma decisiones & 3.85 & 3.31 & .54 \\
\hline Hab. comunic., empatía... & 3.74 & 3.20 & .54 \\
\hline Hab. conjugar situaciones & 3.84 & 3.18 & .66 \\
\hline Hab. mediación en conflic. & 3.81 & 3.29 & .52 \\
\hline Saber planificar y organ. & 3.80 & 3.29 & .51 \\
\hline Cap. gestión econ. y recur. & 3.48 & 3.08 & .40 \\
\hline Resistencia frustaciones & 3.64 & 2.96 & .68 \\
\hline
\end{tabular}

Tabla 6. Características y competencias para el desempeño de la dirección

Por su parte, los promedios más bajos corresponden a autoridad y don de gentes, seguidas por inteligencia, sensibilidad y habilidades de liderazgo, casi todas ellas cualidades tradicionalmente asociadas al liderazgo carismático

En lo que se refiere a las características y competencias que las directoras consideran reunir, destacan responsabilidad y sensibilidad con las medias más altas, $\mathrm{y}$, nuevamente, autoridad y don de gentes con las medias más bajas. En trabajos anteriores hemos detectado también esta tendencia de las mujeres a describirse a sí mismas como responsables y sensibles (Padilla et al. 1999). Nos sorprende gratamente, sin embargo, que las directoras consideren que, entre las características que en menor grado afirman poseer, destaquen aquellas precisamente que han sido valoradas como menos adecuadas para el desempeño de la dirección. Dicho de otra forma, si bien no afirman directamente poseer las características más valiosas para el ejercicio del cargo, sí que denotan no ajustarse al modelo de características de líder carismático que anteriormente han destacado como menos beneficioso para la dirección.

En esta pregunta es interesante hacer un análisis de las diferencias en las respuestas a las dos perspectivas utilizadas (ser valiosa para la dirección y poseer la característica). Ello nos indica qué características consideran las directoras que son valiosas para el cargo en mayor medida que el grado en que afirman poseerla, y con qué características ocurre justo lo contrario.

Como norma, casi todos los aspectos suelen obtener medias más altas en la columna Valiosa para la dirección que en la columna Poseo estas características. Esto implica que las directoras de la muestra consideran que las características y competencias propuestas son valiosas para el desempeño del cargo en mayor medida que ellas la poseen. Se detecta, por tanto, una actitud, podría decirse, humilde por parte de las directoras que han tendido a mostrar una imagen de sí mismas en la que predominan los valores centrales en las medias de todas las competencias y habilidades propuestas. Así, si se observan los promedios en la columna central, estos están comprendidos entre 2.69 y 3.85, valores más bajos que los alcanzados en la columna de la izquierda (relativa al valor de las competencias propuestas para el desempeño del cargo de directora).

En esta línea, la única diferencia negativa entre las medias de las dos columnas -es de- 
cir, la única característica que las directoras reconocen como menos valiosa para la dirección que el grado en que ellas la poseen- es sensibilidad. Esto implica que las directoras se reconocen como más sensibles que lo que resulta necesario para el desempeño del cargo. No obstante, la diferencia entre ambas valoraciones -grado en que es valiosa la característica para la dirección y grado en que se posee- es mínima $(0,07)$.

Entre las diferencias que se manifiestan en el sentido contrario -o sea, las que son valiosas para la dirección en un grado mayor que el que las poseen las directoras-, cabe destacar las siguientes competencias: habilidades de liderazgo (diferencia de 0,73), capacidad de dinamización $(0,7)$, resistencia a las frustraciones $(0,68)$ y habilidad para conjugar situaciones difíciles y conflictivas junto con diplomacia (ambas con 0,66 de diferencia). Es importante hacer notar que muchas de las competencias señaladas se mueven dentro de lo que podríamos considerar como el ámbito de las relaciones sociales (dinamizar, liderar, actuar ante conflictos, tener diplomacia...).

Pasamos ya a comentar las consecuencias que el ejercicio de la dirección tiene o ha tenido en las relaciones con los/as compañeros/as del centro. Como se muestra en la tabla 5 , sólo un $36 \%$ de las directoras afirman que el desempeño del cargo ha afectado a las relaciones con los/as colegas. Entre los aspectos que más se ven afectados, las directoras destacan la distancia en el trato y los enfrentamientos no deseados que a veces genera el ejercicio del poder (opción elegida por el 65.6\%) y el hecho de que sean vistas ahora como controladoras del trabajo (casi un $19 \%)$. Un menor porcentaje de encuesta- das (entre el 3 y el 8\%, según el caso), apuntan que el cambio en las relaciones se manifiesta en una menor confianza, en ser consideradas "de la oposición” o en otros aspectos.

Se les ha preguntado a las encuestadas cuáles son los problemas que encontraron a la hora de desempeñar su actividad directiva (tabla 5 e ilustración 4). La falta de apoyo de la administración y la falta de preparación profesional para asumir esa responsabilidad son los que han obtenido promedios más altos, frente a la falta de apoyo del claustro y encontrar un equipo directivo de confianza, que obtienen las medias más bajas. La actividad de enseñanza no parece ser un problema para el ejercicio de la dirección, desde el punto de vista de su compatibilidad, por parte de las directoras encuestadas. Por tanto, en lugar de identificar al profesorado, se tiende a señalar factores externos al centro (la administración educativa) o internos de las directoras (falta de preparación), como más problemáticos en el desempeño de la dirección.

En cuanto al reconocimiento conseguido en su labor de dirección (tabla 5), las directoras creen que sus colegas del centro valoran su trabajo positivamente (la media obtenida es de 3,05, estando comprendidos los valores entre $1 \mathrm{y} 4$ ). Esto se contradice de alguna forma con la información recabada en torno al grado en que reciben críticas y las fuentes de las mismas. Así, los/as docentes son el colectivo que obtienen el promedio más alto (2.10) frente a las familias (2.03), el alumnado (1.79), la inspección (1.78) y la administración educativa (1.72). 


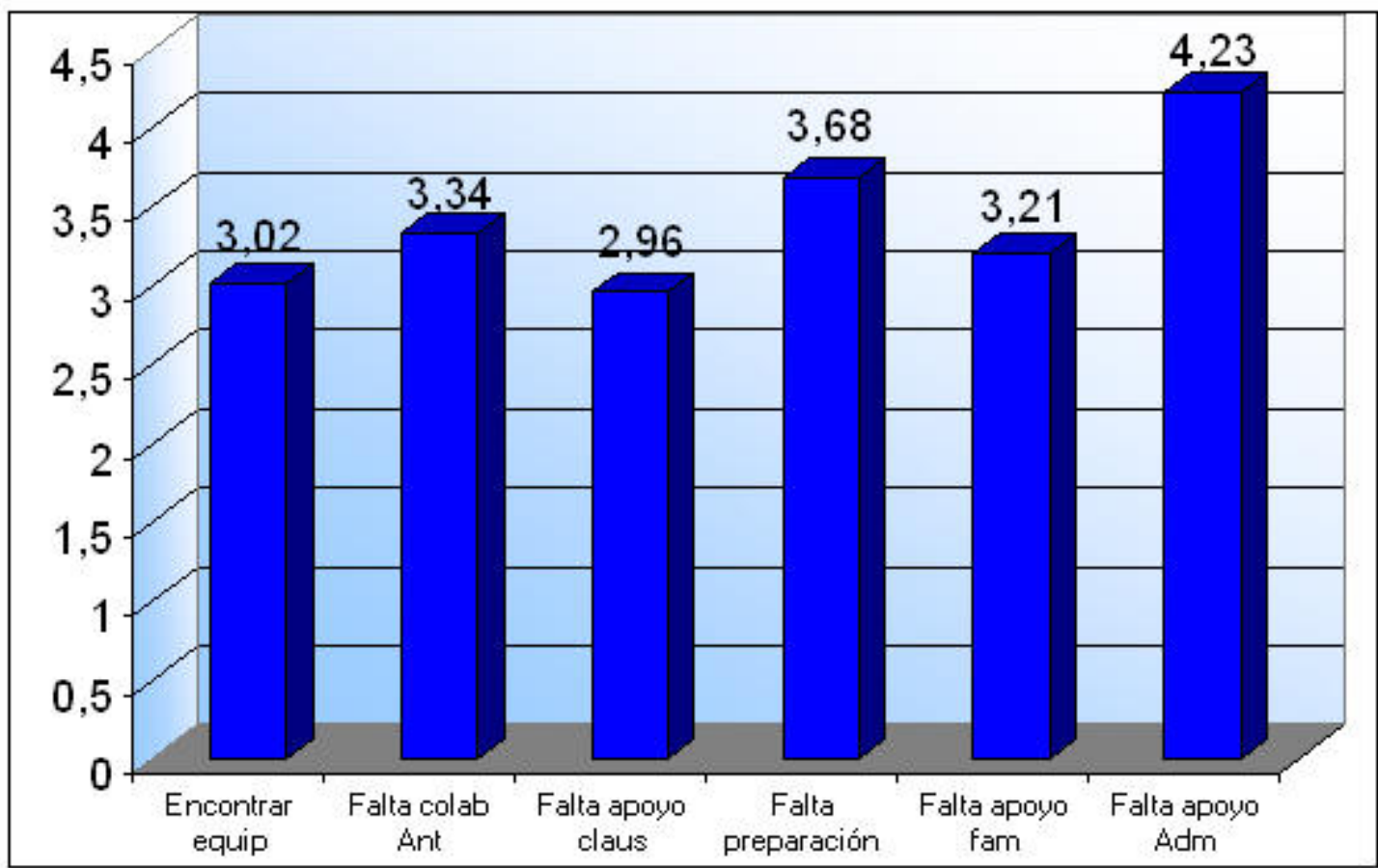

Ilustración 4. Principales problemas encontrados a la hora de acceder al cargo

Evidentemente, para las directoras, resulta más fácil ser criticadas por los colectivos con los que tienen mayor relación o trato (docentes, familias y alumnado), sin embargo, llama la atención el hecho de que estos mismos colectivos no se perciban como causantes de los principales problemas con los que se han encontrado a la hora de desempeñar el cargo (como se indicó anteriormente).

Pasamos ahora a describir los resultados en torno a aspectos clave del trabajo de las directoras. Cuando se les pregunta por las tareas que, según su opinión, tienen mayor y menor importancia en el ejercicio del cargo (ver tabla 5 e ilustración 5), las que aparecen consideradas como más importantes son favorecer un buen clima y la gestión y organización, mientras que los valores más bajos $\mathrm{y}$, por tanto, las que consideran menos importantes- son para representación del centro y localización y provisión de recursos. Subyace, por tanto, una visión de la dirección como facilitadora de las relaciones y del trabajo en el centro, frente al desempeño de un papel más técnico y centrado en el ejercicio del poder. 


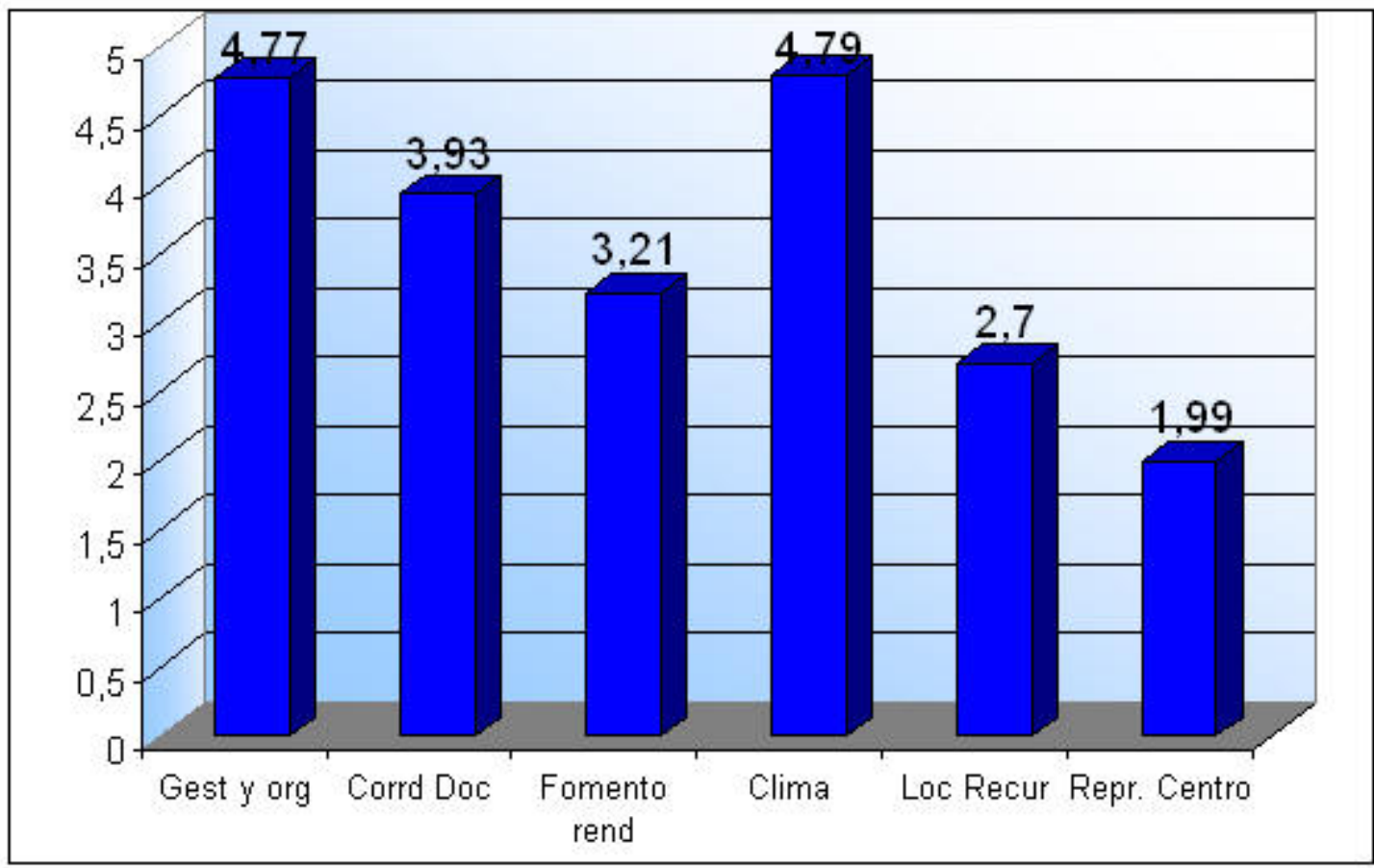

Ilustración 5. Tareas más y menos importantes para el ejercicio de la dirección

Esta perspectiva se aprecia también en los mecanismos que las directoras afirman que suelen utilizar ante los problemas de disciplina (ver tabla 5). Así, más de la mitad de las encuestadas hablan con los/as implicados y llegan a acuerdos, frente a opciones más directivas como ser firme y tomar decisiones rápidas (opción seleccionada sólo por el 4,75\%). Desarrollar programas para mejorar la convivencia y aplicar la normativa y el reglamento de régimen interno son también opciones habituales, aunque no tan frecuentes, para resolver los problemas disciplinarios.

La forma en que estas mujeres entienden la dirección refuerza lo que venimos comentando hasta el momento (ver tabla 5). Para un 85\% de ellas, la dirección es primordialmen- te trabajo en equipo, para el $14 \%$, la dirección es gestión y sólo un $1 \%$ considera que es poder de decisión. El trabajo colegiado y el consenso son, por tanto, los mecanismos que caracterizan la forma en que las directoras de la muestra llevan a la práctica su cargo de directoras.

No obstante, el tiempo que dedican a las diversas tareas asociadas al cargo no refleja siempre esta visión (ver tabla 5 e ilustración 6). Así, las tareas que requieren un promedio mayor de horas son las administrativas y de gestión, junto con otras no indicadas en las opciones iniciales (tales como clases y reuniones). Tareas como liderazgo y coordinación, contacto con familias e información obtienen promedios sensiblemente inferiores. 


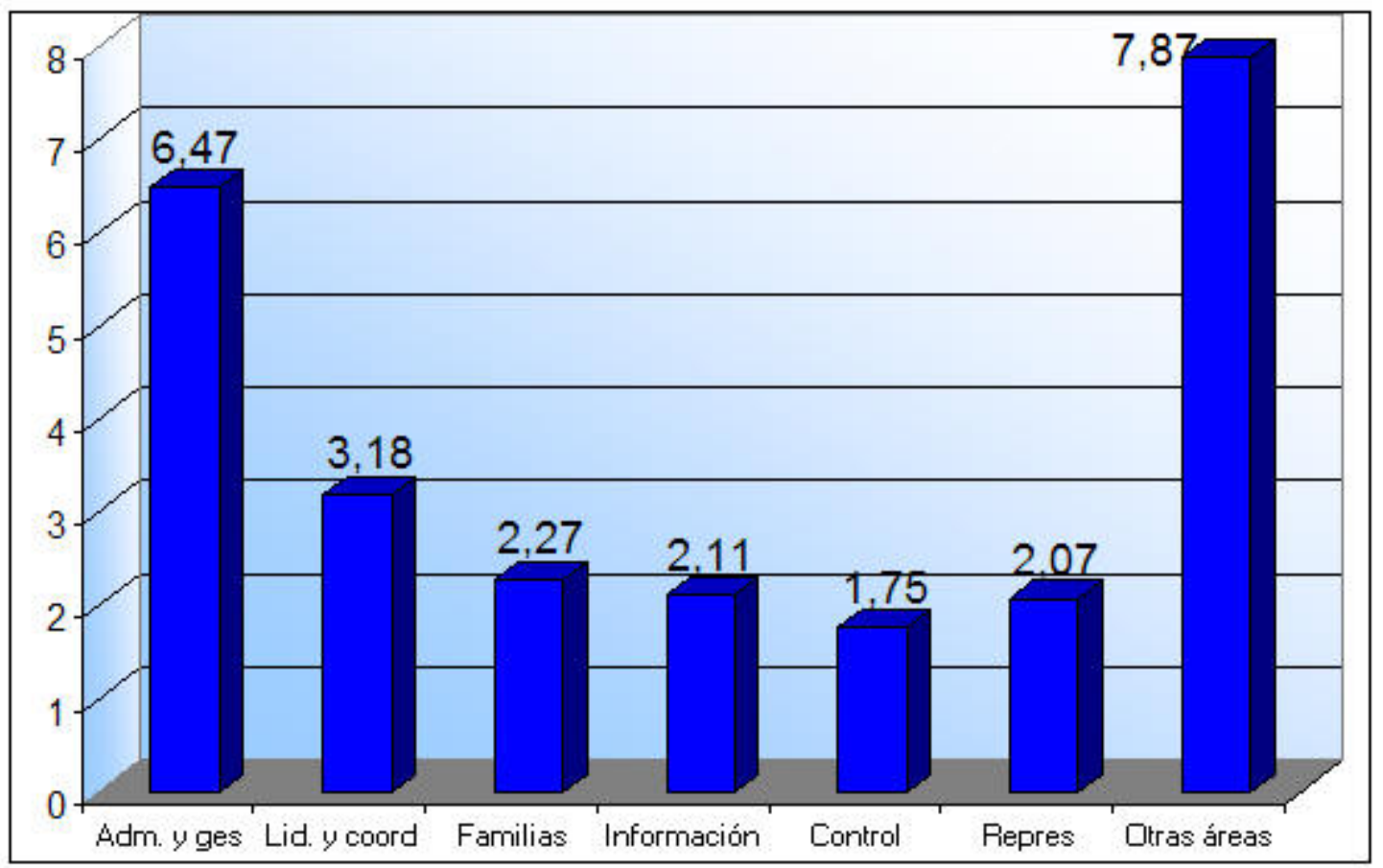

Ilustración 6. Número de horas semanales dedicadas a diferentes tareas

Puede, por tanto, pensarse que una cosa es la forma en que las directoras conciben su cargo y funciones, y otra la realidad del trabajo diario que impone unos condicionantes a lo que estas mujeres desean llevar a cabo.

La última variable comprendida en la dimensión opiniones y experiencias ante la dirección escolar consiste en una valoración, a nivel general, de la propia actuación como directora. En ella hemos obtenido una media de 3,19 (sobre 4) con una desviación típica de 0,63 . Puede decirse que las directoras, con bastante nivel de acuerdo entre ellas, valoran de forma bastante positiva su trabajo. La moda apunta a que la opción que más frecuentemente señalan es creo que necesito mejorar algunos aspectos. En esencia, puede decirse que están satisfechas con sus logros, aunque siguen firmes en su compromiso de mejora.

\section{Diferencias entre las opiniones de las di- rectoras}

Uno de los objetivos del estudio consistía en identificar posibles diferencias de opinión entre las directoras en función de algunas variables socio-demográficas. Estos contrastes se han llevado a cabo entre las siguientes variables:

- Provincia en la que ejerce como directora.

- Nivel educativo que imparte (infantil y primaria).

- Tipo de centro en que trabaja (rural, urbano y urbano-periférico).

- Experiencia docente, distinguiendo entre dos grandes grupos: directoras con menos experiencia (aquellas cuyos años de experiencia son inferiores a la media del grupo) y directoras con más experiencia (que igualan o superan la media de años de experiencia de la muestra).

- Edad (menores de 40 años y con 40 años ó más).

- Cuidado de hijos/as: diferenciando entre las que no tienen ninguna criatura a su cargo y las que sí.

Asimismo, se han seleccionado las variables de comparación que hemos considerado más relevantes, siendo estas: incentivos en el acceso a la dirección (dimensión que incluye 7 incentivos distintos), importancia concedida a distintas tareas en el ejercicio de la di- 
rección (dimensión que agrupa a 6 tareas), mecanismos utilizados en la resolución de problemas, forma en la que concibe la dirección escolar, horas dedicadas a tareas relacionadas con la dirección (dimensión que agrupa el tiempo de dedicación a 7 tareas diferentes) y valoración del propio desempeño como directoras.

En la tabla 7 se presenta el resumen de los principales resultados encontrados. Dado que algunas variables tienen varios indicadores, se indican sólo los casos en que el grado de significación $(p)$ es inferior a a (0.05), y el valor más bajo de $p$ cuando supera al nivel de riesgo utilizado.
Empezando por las diferencias en las opiniones de las directoras de las ocho provincias andaluzas, los correspondientes valores de $\mathrm{F}$ tras los análisis de varianza (y los de chi-cuadrado en el caso de las variables nominales) no aparecen como significativos, lo que indica que existe uniformidad en la opinión de las directoras de todas las provincias. Tampoco se detecta ninguna diferencia entre las directoras con mayor y menor experiencia docente. En este caso, ni los resultados del estadístico t ni los de chi-cuadrado muestran que ambos grupos manifiesten opiniones distintas respecto de las variables consideradas.

\begin{tabular}{|c|c|c|c|}
\hline $\begin{array}{c}\text { VARIABLES } \\
\text { DE } \\
\text { AGRUPACIÓN }\end{array}$ & $\begin{array}{l}\text { VARIABLES A } \\
\text { COMPARAR }\end{array}$ & $\begin{array}{l}\text { PRUEBA } \\
\text { UTILIZADA }\end{array}$ & RESULTADO* \\
\hline \multirow{6}{*}{ PROVINCIA } & INCENTIVOS & \multirow{4}{*}{ ANOVA } & $p$ por encima de $.272(\mathrm{~F}=1.279)$ \\
\hline & \begin{tabular}{|l} 
TAREAS \\
\end{tabular} & & $p$ por encima de $.135(\mathrm{~F}=1.608)$ \\
\hline & HORAS & & $p$ por encima de $.115(\mathrm{~F}=1.689)$ \\
\hline & \begin{tabular}{|l} 
VALOR.DESEMP. \\
\end{tabular} & & $p=.919(\mathrm{~F}=0.370)$ \\
\hline & PROB. DISCIPL. & \multirow{2}{*}{ CHI-CUADRADO } & $c^{2}=26.471^{*}(p=.547)$ \\
\hline & DIRECC. COMO... & & $c^{2}=16.632^{*}(p=.276)$ \\
\hline \multirow{6}{*}{$\begin{array}{l}\text { NIVEL } \\
\text { EDUCATIVO }\end{array}$} & INCENTIVOS & \multirow{4}{*}{$\mathrm{t}$} & $p$ por encima de $.057(\mathrm{t}=-1.929)$ \\
\hline & TAREAS & & $p$ por encima de $.081(\mathrm{t}=1.758)$ \\
\hline & HORAS & & $p$ por encima de $.268(\mathrm{t}=1.133)$ \\
\hline & \begin{tabular}{|l} 
VALOR.DESEMP. \\
\end{tabular} & & $p=.949(\mathrm{t}=-0.064)$ \\
\hline & PROB. DISCIPL. & \multirow{2}{*}{ CHI-CUADRADO } & $c^{2}=17.347(p=.002)$ \\
\hline & DIRECC. COMO... & & $\mathrm{c}^{2}=0.551^{*}(\mathrm{p}=.759)$ \\
\hline \multirow{6}{*}{$\begin{array}{l}\text { TIPO DE } \\
\text { CENTRO }\end{array}$} & INCENTIVOS & \multirow{4}{*}{ ANOVA } & $\begin{array}{l}\text { I3G F }=\mathbf{3 . 7 5 8}(\mathbf{p}=\mathbf{. 0 2 7}) \\
\text { Resto con } p \text { por encima de } .163(\mathrm{~F}=1.843)\end{array}$ \\
\hline & \begin{tabular}{|l|} 
TAREAS \\
\end{tabular} & & $p$ por encima de $.077(\mathrm{~F}=0.926)$ \\
\hline & HORAS & & $\begin{array}{l}\text { I12B F=4.247 }(\mathbf{p}=. \mathbf{0 1 6}) \\
\text { I12E } \mathbf{F}=\mathbf{4 . 8 0 8}(\mathbf{p}=. \mathbf{0 1 0}) \\
\text { Resto con } p \text { por encima de } .155(\mathrm{~F}=1.888)\end{array}$ \\
\hline & VALOR.DESEMP. & & $p=.255(\mathrm{~F}=1.376)$ \\
\hline & PROB. DISCIPL. & \multirow{2}{*}{ CHI-CUADRADO } & $c^{2}=11.349 *(p=.183)$ \\
\hline & DIRECC. COMO... & & $c^{2}=2.711^{*}(p=.607)$ \\
\hline \multirow{6}{*}{$\begin{array}{l}\text { EXPERIENCIA } \\
\text { DOCENTE }\end{array}$} & INCENTIVOS & \multirow{4}{*}{$\mathrm{t}$} & $p$ por encima de $.125(\mathrm{t}=1.543)$ \\
\hline & TAREAS & & $p$ por encima de $.101(\mathrm{t}=-1.649)$ \\
\hline & HORAS & & $p$ por encima de $.061(\mathrm{t}=-1.889)$ \\
\hline & \begin{tabular}{|l} 
VALOR.DESEMP. \\
\end{tabular} & & $p=.633(\mathrm{t}=-0.478)$ \\
\hline & $\begin{array}{l}\text { PROB. DISCIPL. } \\
\end{array}$ & \multirow{2}{*}{ CHI-CUADRADO } & $\mathrm{c}^{2}=2.034(\mathrm{p}=.730)$ \\
\hline & \begin{tabular}{|l} 
DIRECC. COMO... \\
\end{tabular} & & $\mathrm{c}^{2}=4.388^{*}(\mathrm{p}=.111)$ \\
\hline
\end{tabular}

Tabla 7. Principales resultados de los contrastes realizados 


\begin{tabular}{|c|c|c|c|}
\hline \multirow{6}{*}{ EDAD } & INCENTIVOS & \multirow{4}{*}{$\mathrm{t}$} & $\begin{array}{l}\text { I3B } \mathbf{t}=\mathbf{2 . 1 9 4}(\mathbf{p}=. \mathbf{0 3 0}) \\
\text { Resto con } p \text { por encima de } .097(\mathrm{t}=1.671)\end{array}$ \\
\hline & TAREAS & & $\begin{array}{l}\text { I9C } \mathbf{t}=-\mathbf{2 . 4 8 1}(\mathbf{p}=\mathbf{. 0 1 4}) \\
\text { Resto con } p \text { por encima de } .113(\mathrm{t}=1.647)\end{array}$ \\
\hline & HORAS & & $p$ por encima de $.399(\mathrm{t}=0.870)$ \\
\hline & VALOR.DESEMP. & & $p=.116(\mathrm{t}=-1.611)$ \\
\hline & PROB. DISCIPL. & \multirow{2}{*}{ CHI-CUADRADO } & $c^{2}=4.984 *(p=.289)$ \\
\hline & DIRECC. COMO... & & $c^{2}=9.801 *(p=.007)$ \\
\hline \multirow{6}{*}{$\begin{array}{l}\text { CUIDADO DE } \\
\text { HIJOS/AS }\end{array}$} & INCENTIVOS & \multirow{4}{*}{$\mathrm{t}$} & $\begin{array}{l}\text { I3A } \mathbf{t}=-2.912(\boldsymbol{p}=. \mathbf{0 0 4}) \\
\text { I3G } \mathbf{t}=\mathbf{2 . 2 9 7}(\boldsymbol{p}=\mathbf{. 0 2 4}) \\
\text { Resto con } p \text { por encima de } .251(\mathrm{t}=1.158)\end{array}$ \\
\hline & TAREAS & & $p$ por encima de $.129(\mathrm{t}=1.525)$ \\
\hline & HORAS & & $p$ por encima de $.095(\mathrm{t}=1.680)$ \\
\hline & VALOR.DESEMP. & & $p=.232(\mathrm{t}=1.199)$ \\
\hline & PROB. DISCIPL. & \multirow{2}{*}{ CHI-CUADRADO } & $\mathrm{c}^{2}=7.096(\mathrm{p}=.131)$ \\
\hline & DIRECC. COMO... & & $c^{2}=3.184 *(p=.203)$ \\
\hline
\end{tabular}

(*) En los valores observados de chi-cuadrado, el asterisco indica que no se cumple alguna de las dos condiciones necesarias en esta prueba (más del $20 \%$ de las celdillas presentan frecuencia esperada inferior a 5 o en alguna celdilla el valor de la frecuencia esperada es inferior a 1).

Tabla 7. Principales resultados de los contrastes realizados (continuación)

En términos generales, no existen diferencias entre las opiniones respecto de la dirección escolar manifestadas por las directoras de infantil y primaria. Ambos grupos coinciden en cuestiones como los incentivos que tuvieron a la hora de acceder a la dirección, la importancia que atribuyen a diferentes tareas relacionadas con la misma, el tiempo que dedican a estas tareas, etc. Tan sólo cabe destacar que las directoras de infantil poseen una opinión distinta a las de primaria en cuanto a la forma en que solucionan los problemas de disciplinas.

Sí existen algunas diferencias de opinión entre las directoras que lideran centros rurales, urbanos y urbanos-periféricos, pero estas diferencias se dan sólo en algunos indicadores aislados de las dimensiones incentivos en el acceso a la dirección (concretamente, prestigio social -I3G-) y horas dedicadas a distintas tareas (liderazgo pedagógico I12B- y coordinación y control -I12C-).

Para saber entre qué grupos se dan estas diferencias es necesario acudir a la prueba de Scheffé, en la que, según los contrastes que arrojan valores de $p$ significativos, puede afirmarse que:
- Las directoras de centros urbanos concedieron mayor importancia al prestigio social como incentivo para acceder al cargo que las de centros rurales ( $p=.038$ ).

- Las directoras de centros rurales dedican más tiempo a la tarea de liderazgo pedagógico y coordinación que las directoras de centros urbanos-periféricos ( $p=.016)$.

- Las directoras de centros urbanos $(p=.029) \quad y$ las de urbano-periféricos $(p=.039)$ dedican más tiempo a la tarea de control que las directoras de centros rurales.

En cuanto a la variable edad, existen algunas diferencias de opinión entre las directoras más jóvenes y las más mayores. Así, la liberación total/parcial de la docencia (ítem I3B) tiene más importancia para el primer grupo como incentivo para acceder a la dirección. Además, fomentar el rendimiento del alumnado (I9C) es una tarea más importante para las de mayor edad, y ambos grupos entienden de forma distinta la dirección del centro escolar.

Finalmente, entre las directoras con hijos/as y las que no lo tienen las únicas diferencias significativas se encuentran en dos de los incentivos para acceder a la dirección: la 
remuneración (I3A) y el prestigio (I3G). El primero de ellos es más importante para las que tienen hijos/as a su cuidado, mientras que el segundo tiene mayor importancia para las que no los/as tienen.

\section{DISCUSIÓN Y CONCLUSIONES}

A la vista de los resultados presentados se destaca que las docentes que ejercen la dirección del centro suelen ser aquellas que reúnen tanto una dilatada experiencia profesional como un amplio tiempo de trabajo en el mismo centro. En la gran mayoría de los casos, además, han probado con anterioridad el ejercicio de cargos como la jefatura de estudios, la secretaría del centro y otros.

Como cabe esperar de este perfil profesional, las directoras son mujeres de mediana edad en adelante, pudiendo afirmarse que su situación vital/personal se encuentra relativamente libre de cargas familiares: más de una cuarta parte no tiene a nadie a su cargo y el resto tiene hijos/as cuyas edades no requieren tanta dedicación. En el estudio desarrollado en el contexto onubense por Carrasco (2002), se encuentran resultados muy similares: un 25\% de las directoras encuestadas no tienen hijos/as y un $67 \%$ de las que sí tienen hijos/as, accedieron al cargo cuando estos/as son mayores. También Sánchez Moreno (2005) encuentra un perfil similar entre las gestoras de las universidades españolas.

De acuerdo con lo anterior, puede afirmarse que la dirección escolar no es una alternativa frecuente para las docentes más jóvenes, con menos experiencia y con hijos/as en edades que demandan mayor atención y cuidado. De cara a futuras investigaciones, no obstante, sería necesario trabajar también con una muestra masculina, de forma que podamos comprobar si, en el caso de los varones, se da también esta tendencia o, por el contrario, existe mayor diversidad entre los directores en cuanto a la edad, la experiencia, la antigüedad y las cargas familiares. En este sentido, puede servirnos de referente el estudio de Díez Gutiérrez (2004) quien, usando una muestra nacional de directoras y directores, encuentra que hay más mujeres que hombres en puestos directivos (un 27.02\% frente a un $15.13 \%$ ) que manifiestan expresamente no tener cargas familiares. En esta investigación, en el caso de las mujeres, se percibía como "una ventaja el no tener hijos/as o responsabilidades familiares que (le) ataran para poder desempeñar la dirección “(p. 56).

En lo relativo a las opiniones y experiencias en la dirección escolar, puede destacarse que las directoras afirman que la gestión y la dirección del centro afecta, sobre todo, a su tiempo personal fuera del centro y a funciones más académicas -preparar e impartir clases-, que de relación personal -sus responsabilidades domésticas y la atención a los problemas del alumnado-, resultados que coinciden con los del estudio de Díez Gutiérrez (2004). Con un matiz algo distinto, en el estudio de García Gómez (2006) se pone de manifiesto que las maestras consideran que desempeñar un puesto directivo obstaculiza su trabajo como enseñantes, viéndose afectada la calidad de la enseñanza y la relación que mantienen con el alumnado.

Entre los motivos para acceder a la dirección predominan los altruistas -mejorar la realidad del centro- o internos -satisfacción personal- frente a razones más pragmáticas o materialistas (poder, remuneración, prestigio,...). Aunque, obviamente, esta visión puede estar distorsionada por la deseabilidad social, la encuesta sobre la función directiva realizada por el INCE en el año 2000 ya mostraba claramente que la razón más frecuentemente manifestada por los directores y directoras para explicar la motivación que les había llevado a la dirección era la de llevar a cabo un proyecto pedagógico determinado. En el nivel universitario, la investigación desarrollada por Sánchez Moreno (2005) pone igualmente de manifiesto que el acceso a la gestión por parte de las mujeres se encuentra vinculado a la satisfacción personal y al desarrollo de un proyecto de grupo. 
En otro orden de cosas, las directoras encuestadas no consideran que sean especialmente valiosas para el cargo aquellas características y competencias que tradicionalmente se asocian al liderazgo carismático (como autoridad y don de gentes, inteligencia, sensibilidad, habilidades de liderazgo), valorando más positivamente otros aspectos como la responsabilidad y la capacidad de toma de decisiones. En el estudio de Carrasco (2002) se pone de manifiesto que las directoras se valoran de forma más baja en aquellos rasgos que son propiamente de gestión, tendiendo a valorarse mejor en los rasgos relacionados con el sentido de la justicia, la honestidad y sinceridad, el ser una persona cercana, negociadora, etc.

En cuanto a las consecuencias que el acceso al cargo ha tenido en la relación con sus colegas, la mayoría afirma que esta relación no ha cambiado. Aunque en el tercio de encuestadas que afirman que sí ha habido un cambio, este se traduce en un mayor distancia en el trato con los compañeros y compañeras, coincidiendo una vez más con los resultados del estudio de Díez Gutiérrez (2004). Es interesante recordar aquí que aunque afirman tener el reconocimiento de sus colegas, son estos/as los/as que suelen hacer más críticas a su labor, frente a otros colectivos como las familias, el alumnado y la administración.

Entre los problemas encontrados para el desempeño de la dirección, destaca la falta de apoyo de la administración y la insuficiente preparación profesional. Los posibles problemas relacionados con el apoyo de colegas y familias aparecen en los últimos lugares. Estos resultados coinciden con los del estudio de Díez Gutiérrez (2004), así como parcialmente con los del estudio de Caballero (2004) sobre la satisfacción de directores y directoras de la C.A. Andaluza, en el que se encuentra que las relaciones con la administración educativa y municipal es el ámbito que produce mayor insatisfacción en este colectivo. También en las relaciones con los padres y madres existe una insatisfacción moderada, mientras que aspectos como la interacción director/a-alumno/a y las relaciones con los/as compañeros/as producen un grado de satisfacción moderado. Estos hallazgos en cuanto a la satisfacción de los/as directores/as se repiten también en una muestra de secretarios/as de centro (Caballero, Fernández y García, 2003) y de jefes/as de estudio (Caballero, 2003) de la misma comunidad.

En relación a la forma en que las directoras entienden su trabajo, destacamos que las encuestadas valoran positivamente su actuación, aunque consideran que deben mejorar todavía en algunos aspectos. Consideran que su función es eminentemente facilitadora. Para ellas, la dirección es primordialmente trabajo en equipo. Así, favorecer un buen clima y desarrollar la gestión y organización del centro son las tareas que consideran más importantes. Además ante situaciones problemáticas, como los asuntos de disciplina, tienden a usar el diálogo y la negociación. Estos resultados son similares a los encontrados por Carrasco (2002). No obstante, la dedicación de tiempos a las diversas tareas asociadas a la dirección no siempre refleja esta visión, dedicando muchas horas a las labores administrativas y de gestión, al igual que sucede en el estudio de Díez Gutiérrez (2004).

En cuanto a las diferencias en las opiniones manifestadas por las directoras, hemos de destacar que dichas diferencias son muy escasas y se dan sólo en algunos indicadores concretos y no en las dimensiones consideradas en su conjunto. Parecen, por tanto, poco relevantes desde el punto de vista de su interpretación, lo que viene a reforzar la consistencia y universalidad de las opiniones vertidas en el cuestionario. En este análisis, una de las cuestiones que cabe señalar es una distinta forma de considerar tanto la importancia de ciertos incentivos para acceder al cargo, como la de ciertas tareas asociadas al mismo en función del tipo de centro. Así, 
mientras las directoras de centros rurales dedican más tiempo a ejercer un liderazgo pedagógico y de coordinación, sus colegas de centros urbanos y urbanos-periféricos no comparten esta opinión, dedicando más tiempo a la tarea de control. A su vez, las directoras de centros urbanos se diferencian de las de centros rurales en la importancia que conceden al prestigio social como incentivo para acceder al cargo. Sería necesario profundizar en estas diferencias en futuros estudios a fin de identificar si el desempeño de la dirección tiene motivaciones y significados distintos en los centros rurales y urbanos.

En cualquier caso, este estudio debe considerarse como una aportación parcial que se ha centrado en las opiniones de las directoras sobre su desempeño de la dirección escolar. Obviamente estas opiniones deben ser comparadas en futuras investigaciones con las de otros grupos implicados como el profesorado, la inspección educativa, el alumnado y sus familias, etc.

Para finalizar, queremos insistir en la idea de que este trabajo sólo ha realizado una exploración inicial de la experiencia femenina en la dirección de los centros escolares, siendo necesario profundizar en el tema, especialmente a través de estudios de caso que documenten con mayor detalle los estilos de liderazgo ejercidos por las mujeres. Conocer las acciones llevadas a cabo por ellas como agentes implicados en el proceso educativo puede convertirse en una herramienta valiosa para comprender la naturaleza y el desarrollo de los procesos de gestión y liderazgo. Se trata de reconocer el impacto del género en la vida de las organizaciones educativas como un componente esencial para conocer y comprender el liderazgo educativo.

\section{REFERENCIAS}

Asplund, G. (1998). Women managers. Changing organizational cultures. Manchester: John Wiley \& Sons.
Bardisa, T. (1995). La participación democrática en las instituciones educativas. En J. García y F. Delgado (Coords.), Los retos de la educación ante el siglo XXI, pp. 125-142. Madrid: Editorial Popular.

Barquín, J. y Melero, M.A. (1994). Feminización y profesión docente. Internalización sexista del trabajo. Investigación en la escuela, 22, 25-34.

Batanaz, L. (2005). El acceso a la dirección escolar: problemas y propuestas. Revista Española de Pedagogía, 232, 443-470.

Caballero, J. (2003). Satisfacción e insatisfacción de los jefes de estudios de los centros escolares. Revista de Investigación Educativa, 21 (2), 415-435.

Caballero, J., Fernández Camacho, Carmen R. y García Jiménez, Eduardo (2003). Satisfacción de los secretarios de centros educativos. Revista Electrónica de Investigación y Evaluación Educativa, v. 9, n. 2. Consultado en http://www.uv.es/RELIEVE/v9n2/RELIEV Ev9n2_7.htm el 23 de mayo de 2008.

Caballero, J. y Salvador, F. (2004). Satisfacción e insatisfacción de los directores escolares. Revista de Educación, 333, 363-384.

Capper, C. (1995). Empowering Ieadership. Similarities and contradictions in critical, poststructural and feminist, otherist perspectives. Annual meeting of the AERA, San Fco.

Carrasco, M.J. (2002). Análisis e incidencias de los estilos directivos de las mujeres en centros escolares de contextos desfavorecidos. Tesis doctoral. Universidad de Huelva.

Coronel, J.M. (1996). La investigación sobre el liderazgo y procesos de cambio en los centros educativos. Huelva: Servicio de Publicaciones de la Universidad.

Coronel, J. M. (2003). Liderazgo y gestión en las organizaciones educativas: algunas tareas pendientes de resolver, algunas propuestas para desarrollar. Organización y Gestión Educativa, 6, 9-13.

Coronel, J.M. (2005). El liderazgo del profesorado en las organizaciones educativas: temáticas para su análisis e investigación. 
Revista Española de Pedagogía, 232, 471490.

Coronel, J.M., Moreno, E. y Padilla, M.T. (2002). La gestión y el liderazgo como procesos organizativos: Contribuciones y retos planteados desde una óptica de género. $R e$ vista de Educación, 327, 157-168.

Diéz Gutiérrez, E. (Dir.) (2004). La cultura de género en las organizaciones escolares: motivaciones y obstáculos de acceso de la mujer a los puestos de dirección. Madrid: Instituto de la Mujer. Consultado en http://www.mtas.es/mujer/mujeres/estud_in ves/630.pdf el 15 de enero de 2008.

Donaldson, G.A. (2000). Cultivating leadership in schools. New York: Teacher College Press.

Doyle, M.E. y Smith, M.K. (2001). Shared leadership. The encyclopedia of informal education. Consultado en http://www.infed.org/leadership/shared_lea dership.htm el 15 de enero de 2006.

Elmore, R.F. (2000). Building a new structure for school leadership. New Jersey: The Albert Shanker Institute. Consultado en http://www.shakerinstitute.org/ el 15 de enero de 2006.

Fennell, H. (1997). A passion for excellence: Feminine faces of leadership. Annual meeting of the AERA, Chicago.

Gago, F.M. (2003). La dirección de los institutos. El liderazgo educativo que nunca existió. Organización y Gestión Educativa, 6, 14-23.

García Gómez, T.(2006). La reproducción de estereotipos sexuales en las escuelas: un mecanismo de exclusión de las maestras del cargo de dirección, Bordón, 58 (1), 33-50.

Gento, S. y Ruíz, I. (1996). Liderazgo pedagógico del director de una institución educativa de calidad. En Villa, A. (Coord.). Dirección Participativa y Evaluación de Centros, pp. 631-637. Bilbao: ICE, Universidad de Deusto-Mensajero.

González, M. T. (2003). Organización y Gestión de Centros Escolares. Dimensiones y procesos. Madrid: Prentice-Hall.

Goldring, E. y Chen, M. (1992). The feminization of principaship in Israel: the trade off between political power and cooperative Ieadership. London: Falmer Press.

Grace, G. (1995). School leadership: Beyond education management. London: Falmer Press.

Grañeras, M. (2003). Las mujeres en los equipos directivos de los centros escolares en España. Organización y Gestión Educativa, 3, 15-20.

Hall, V. y Southworth, G. (1997). Headship. School Leadership \& Management, 17 (2) 162-170.

Hurty, K. (1995). Women principals leading with power. New York: SUNY Press.

INCE (2001). Evaluación de la función directiva 2000. Madrid: INCE. Consultado en http://ince.mec.es/ri/index.htm el 31 de mayo de 2008.

Lips, H. (1991). Women, Men and Power. Mountain View: Mayfield Publisbing Comp.

Mertz, N. (1995). Journey into the theoretical gap: A study of female high shool principals "lived experience". Annual meeting of the AERA, San Fco.

Morrison, K. (2002). School leadership and Complexity theory. Londres: Routledge Falmer.

Muñoz-Repiso, M. (2003). Mujeres, educación y toma de decisiones en la Unión Europea. Organización y Gestión Educativa, 3, 26-31.

Padilla, M.T., Sánchez, M., Martín, M. y Moreno, E. (1999). Análisis de los estereotipos sexistas en una muestra de estudiantes de CC. de la Educación. Revista de Investigación Educativa, 17, 1, 127-147.

Reynolds, C. (1995). Feminist frameworks for the study of administration and leadership in educational organizations. En Reynolds, C. y Young, B. (Eds). Women and Leadership in Canadian Education, pp. 317. Calgary: Detselig.

Rost, J. (1994). Moving from individual to relationship: a postindustrial paradigm of leadership. Annual meeting of the AERA, New Orleans.

Sánchez Moreno, M. (Dir.) (2005). La mujer en la dirección y gestión de las organiza- 
ciones universitarias: problemática, estilos de liderazgo y contribución al desarrollo institucional. Madrid: Instituto de la Mujer. Consultado

en

http://www.mtas.es/mujer/mujeres/estud_in ves/669.pdf el 25 de mayo de 2008.

\section{NOTAS}

[1] Desviación típica, en adelante D.T.

[2] Por este orden: clases y reuniones

[3] Los valores están expresados en promedios de importancia que pueden oscilar entre 1 y 5 .

\section{ARTICLE RECORD / FICHA DEL ARTÍCULO}

\section{Reference / \\ Referencia}

Title /

Título

Authors /

Autores

Review

/ Revista

ISSN

Publication

date /

Fecha de publicación

Abstract /

Resumen
Padilla Carmona, M. Teresa (2008). Opiniones y experiencias en el desempeño de la dirección escolar de las mujeres directoras en Andalucía. RELIEVE, v. 14, n. 1.

http://www.uv.es/RELIEVE/v14n1/RELIEVEv14n1_1.htm. Consultado en (poner fecha).

Opiniones y experiencias en el desempeño de la dirección escolar de las mujeres directoras en Andalucía. [Andalusian women principals' opinions and experiences about their school management performance]

Padilla Carmona, M. Teresa

Revista ELectrónica de Investigación y EValuación Educativa (RELIEVE), v. 14, n. 1

$1134-4032$

2008 (Reception Date: 2008 May 31; Approval Date: 2008 June 23; Publication Date: 2008 June 29)

This paper aims to identify the opinions and experiences in school management held by women principals in Andalusian early and elementary public schools. Using the survey method, data were collected through a questionnaire from a sample of 206 principals selected through a several-stages procedure. Results show that most women principals were middle-aged, have an extensive professional experience and have no children or other people under their care. They occupied the headship due to altruistic and personal reasons, and they considered the lack of support from Educational Administration as the main problem they have to cope. Also, they conceived their work as a team effort with a facilitator function.

Este trabajo persigue identificar las opiniones y experiencias ante la dirección escolar de las directoras de centros públicos de Educación Infantil y Primaria en Andalucía. Se realizó un estudio tipo encuesta con una muestra de 206 directoras seleccionada mediante un muestreo polietápico, utilizando el cuestionario para la recogida de información. Los resultados muestran que las directoras tienen mediana edad, una dilatada experiencia profesional y, en su mayoría, están relativamente libres de cargas familiares. Accedieron al cargo por razones altruistas y personales, y señalan la falta de apoyo de la Administración como su principal problema. Conciben su función como una labor de equipo eminentemente facilitadora.

Keywords / School management perfomance; educational leadership; women principals; survey; leadership profile Descriptores Desempeño de la dirección escolar; liderazgo educativo; mujeres directoras; estudio tipo encuesta.

Institution / Institución

Universidad de Sevilla (España).

Publication

site /

http://www.uv.es/RELIEVE

Dirección

Language /

Idioma

Spanish (Title, abstract and keywords in English ) 


\title{
$\underline{\text { ABOUT THE AUTHORS / SOBRE LOS AUTORES }}$
}

Padilla Carmona, M. Teresa (tpadilla@us.es). Doctora en Pedagogía y Profesora Titular de Métodos de Investigación y Diagnóstico en Educación de la universidad de Sevilla. Sus líneas de investigación en la actualidad son: desarrollo profesional, desarrollo profesional femenino, análisis del sexismo en el ámbito educativo, evaluación del aprendizaje en la Universidad. Su dirección postal es C/ Camilo José Cela s/n. Departamento MIDE. Facultad de Educación. Universidad de Sevilla. 41018 - Sevilla (España). Buscar otros artículos de este autor en Scholar Google Google

\section{Revista ELectrónica de Investigación y $\mathbf{E V}$ aluación Educativa (RELIEVE)}

\author{
[ ISSN: 1134-4032 ]
}

(C) Copyright, RELIEVE. Reproduction and distribution of this articles it is authorized if the content is no modified and their origin is indicated (RELIEVE Journal, volume, number and electronic address of the document).

(C) Copyright, RELIEVE. Se autoriza la reproducción y distribución de este artículo siempre que no se modifique el contenido y se indique su origen (RELIEVE, volumen, número y dirección electrónica del documento). 